Research Article

\title{
Nonlinear Numerical Modeling of the Wire-Ring Net for Flexible Barriers
}

\author{
Zhixiang Yu $\mathbb{D}^{1},{ }^{1,2,3}$ Chun Liu $\mathbb{D}^{1},{ }^{1}$ Liping Guo, ${ }^{1}$ Lei Zhao ${ }^{\mathbb{D}},{ }^{1}$ and Shichun Zhao ${ }^{1,2}$ \\ ${ }^{1}$ Department of Civil Engineering, Southwest Jiaotong University, Chengdu 610031, Sichuan, China \\ ${ }^{2}$ Research Center for Protection Structures against Natural Hazards, Southwest Jiaotong University, Chengdu 610031, \\ Sichuan, China \\ ${ }^{3}$ Shock and Vibration of Engineering Material and Structure Key Laboratory of Sichuan Province, Mianyang 621010, \\ Sichuan, China
}

Correspondence should be addressed to Chun Liu; lc1510596295@163.com

Received 22 May 2019; Accepted 11 September 2019; Published 13 October 2019

Academic Editor: Marco Tarabini

Copyright (c) 2019 Zhixiang Yu et al. This is an open access article distributed under the Creative Commons Attribution License, which permits unrestricted use, distribution, and reproduction in any medium, provided the original work is properly cited.

To investigate the nonlinear mechanical behavior of the wire-ring net, this paper presents a new numerical model that can collectively consider equivalence between numerical and actual wire rings. Quasi-static tests, including tensile tests on steel wires and one-ring specimens, and puncturing tests on net specimens were conducted. Based on the test results, the axial constitutive curves of steel wires were obtained. The linear correlation equations for the breaking loads of the one-ring specimens and the puncturing strength of wire-ring nets were established, both of which were related to the number of windings. The wire rings were modeled via an equivalent structure with a single winding and a circular cross section. Equivalence between the numerical and actual wire rings in terms of bending and tensile strength, total mass, contact with sliding friction, and rupture behavior were also derived and presented. In particular, the emphasis was on simulating the flattening effect, a phenomenon rarely accounted for in conventional numerical models. All dominant factors were reflected in a model with the material law by the input of material parameters. The proposed mechanical model was calibrated and verified by the data from the tests of the wire-ring net. The calibrated mechanical model is also shown to successfully simulate a full-scale test of a flexible rockfall protection barrier according to the ETAG027 standard.

\section{Introduction}

Flexible barriers are increasingly used for the protection from natural hazards such as rockfall, shallow landslides, and debris flow in mountainous terrain due to their low cost and environmental impact [1-3]. Flexible barriers use steel nets with support cables, guiding the impact energy toward energy-absorbing devices, where the energy is dissipated by plastic deformation and frictional processes. The steel net is an important component, and its function is to bear the direct impact of the mass and to transmit the stresses to the connection components, the support structure, and the foundations [4]. The wire-ring net, one of the several net types as, for example, hexagonal meshes [3] or water dropshaped meshes [5], exhibits interestingly complex nonlinear properties, making their usage advantageous for a wide range of engineering protection structures (Figure 1). However, the wire-ring net allows the rings to vary their positions with respect to each other when the net is loaded. The net is therefore very flexible, and an optimal configuration of the rings within the net is achieved in response to the rocks' impact, meaning that the bearing capacity and deformation capacity of the wire-ring net are superior to that of the hexagonal net and chain net $[6,7]$. The wire-ring net shows complex nonlinear mechanical properties due to the under loading geometry of the ring, the nonlinear ring-toring contact, and the nonlinear material law of steel wire. Upon impact, these nonlinear mechanical properties are reflected by mechanical phenomena, including the bending and tensile stages of a wire ring, ring-to-ring contact with 

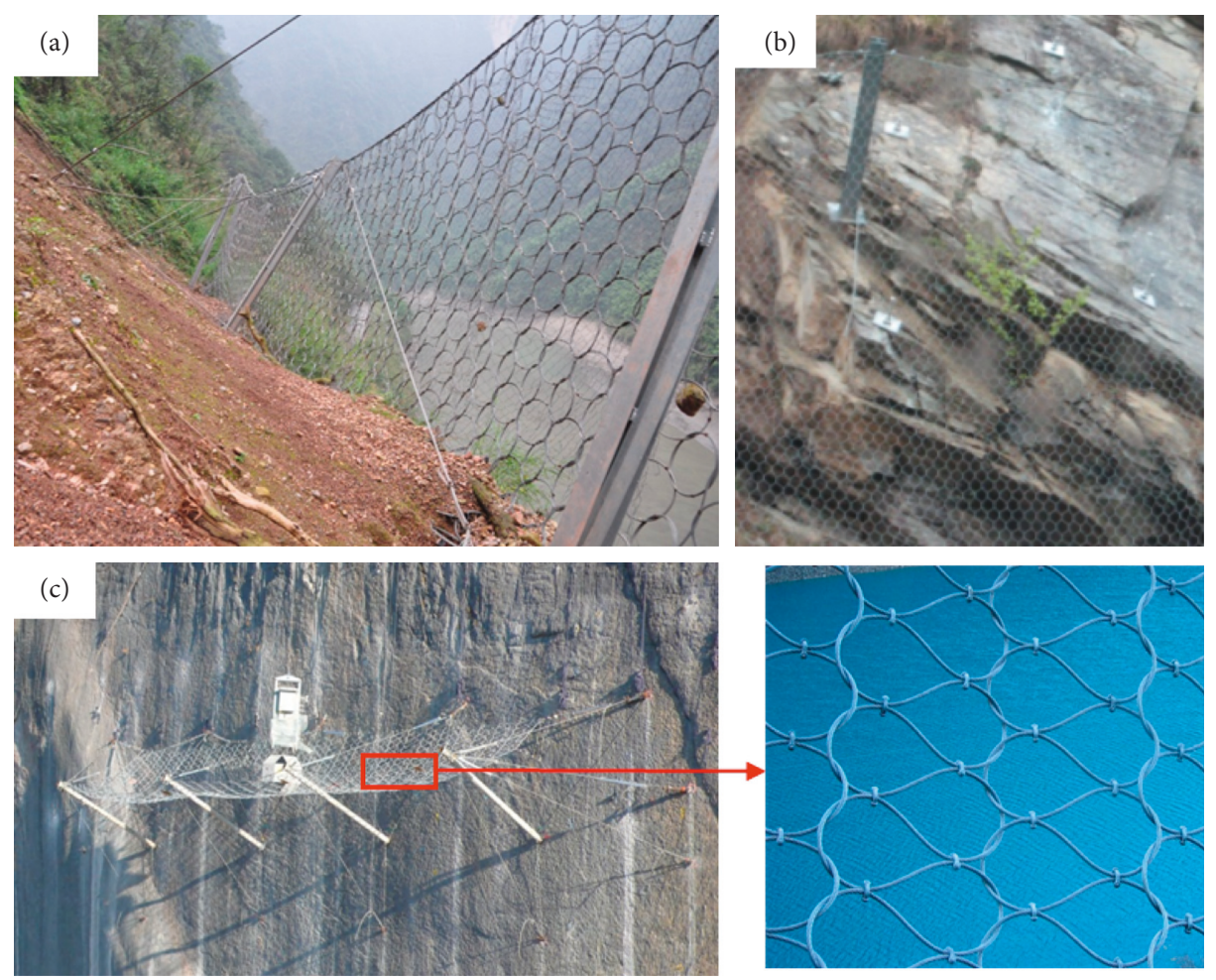

FIGURE 1: Several net types in protection barriers: (a) wire-ring net, (b) hexagonal meshes [3], and (c) water drop-shaped meshes [5].

sliding friction, the flattening effect of steel wire bundles, and the rupture behavior of steel wire $[5,8,9]$. These nonlinear processes result in highly complex analyses and wire-ring net designs, making it a subject for challenging research.

Current theoretical developments are hardly suitable for such analyses due to the complicated nonlinear behavior of the wire-ring net. Furthermore, component tests are slow and costly [10]. Therefore, numerical simulations are a costeffective engineering tool, but the numerical models must be realistic, computationally efficient, and verified with independent tests. Deriving accurate equivalent models that can reproduce the highly nonlinear behaviors of nets is thus of great importance. This investigation presents equivalent approaches that can collectively consider equivalence between numerical and actual wire rings in terms of bending and tensile stages, total mass, contact with sliding friction, the flattening effect, and the rupture behavior of nets.

The existing numerical models for the wire-ring net mainly focus on three aspects: the simulation elements, the mechanical properties of wire rings during bending and tensile regimes, and the contact with sliding friction among the wire rings. Nicot et al. [11] introduced a ring-net model based on the discrete element method (DEM), where rings are discretized into a single node, and the mass nodes are connected with fictive bar (Figure 2(a)). Instead of the discrete element method, Gentilini et al. [12] developed a finite element model, where the spherical hinges at the center of the rings are connected by truss elements (Figure 2(b)). Grassl [10] developed an eight-node FEM model, where the resistance due to traction and bending is modeled with eight bars and eight spring elements per ring, and the ends of the bar elements are connected to mass nodes (Figure 2(c)). Volkwein [13] developed a four-node FEM model with diagonal mass nodes connected by diagonal tension-only springs and adjoining mass nodes connected by circumferential springs (Figure 2(d)). Zhao et al. [14] and Escallón et al. [15] proposed a no-slip equivalent model (Figure 2(e)) and an equivalent ring model (Figure 2(f)), respectively. In both cases, the wire ring was modeled as an equivalent ring, meshed with linear beam elements with a circular cross section by Zhao et al. [14] and Escallón et al. [15].

The mechanical properties of wire rings during bending and tensile regimes were considered by the simplified uniaxial tensile test curves of wire rings with two stages ([10-15], on which the constitutive behavior modeling for the ring was established. Escallón et al. [15] used the area reduction method to account for the mechanical properties of bending and tensile regimes, and the elements were formulated with an elastoplastic constitutive behavior. Constitutive parameters were obtained by genetic algorithm, a breakthrough in the mechanical modeling of the wire-ring net.

Nicot et al. [11], Grassl [10], Volkwein [13], Gentilini et al. [12], and Zhao et al. [14] neglected the contact slide friction among each wire ring, but Escallón et al. [15] accounted for ring-to-ring contact. The introduction of contact with sliding friction is a great improvement in the calculation accuracy of a flexible protection system.

It is also important to consider the mass of the wire ring and the rupture behavior in a model. The mass will affect the transmission of inertia force [10-14]. For example, when a 


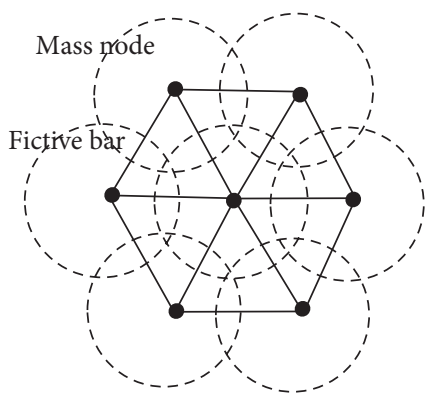

(a)

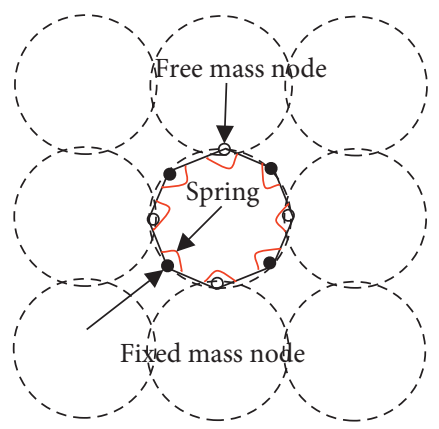

(c)

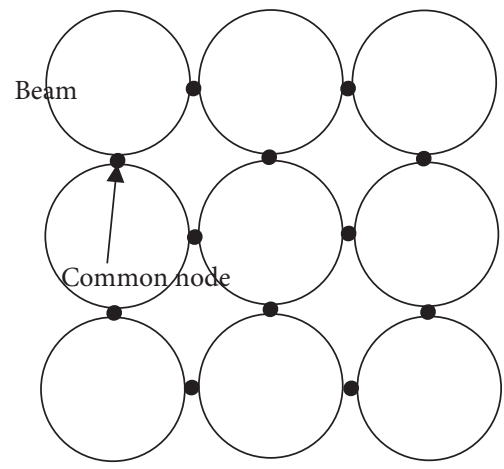

(e)

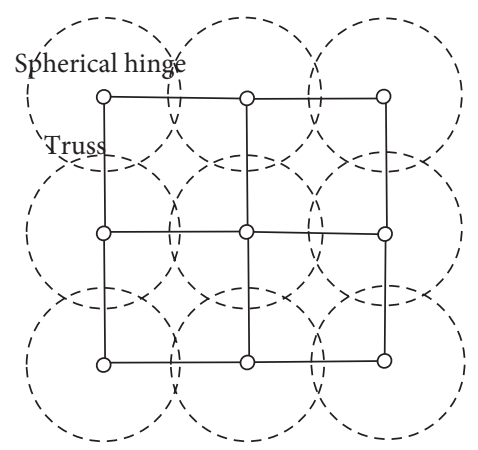

(b)

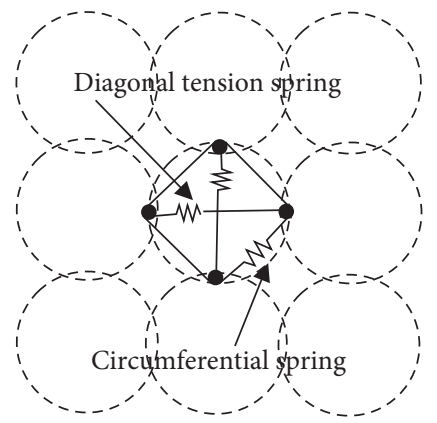

(d)

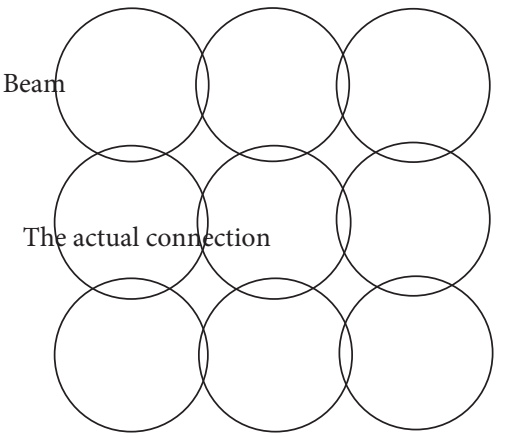

(f)

Figure 2: Mechanical models of the wire-ring net: (a) DEM model [11], (b) FEM model [12], (c) eight-node model [10], (d) four-node model [13], (e) no-slip equivalent model [14], and (f) equivalent ring model [15].

rockfall with mass $m_{\mathrm{r}}$ impacts on a net with mass $m_{\mathrm{n}}$ that moves together with the rockfall by a certain acceleration $a$, the inertial force of the net accounts for $\psi=m_{\mathrm{n}} /\left(m_{\mathrm{n}}+m_{\mathrm{r}}\right)$ of the total inertial force. $\psi$ is related to the participation mass of the net and rockfall mass and varies widely. For example, when the mass of a rockfall is $800 \mathrm{~kg}$ and the mass of a net moving with rockfall at the same acceleration is $200 \mathrm{~kg}$, it can reach $20 \%$. The failure consideration of the model can simulate the rupture behavior of the wire ring. These two factors should not be ignored $[13,15]$. About the flattening effect, up to now, no specific analysis has been made by scholars. Escallón et al. [15] alone mentioned (but left unanalyzed) the flattening effect of steel wire bundles at the contact zones.

In addition, Trad et al. [7] studied the pear shape net, which is similar to the wire ring net and proposed a pear shape net model. The model considered the equivalence between calculation model and actual net, including bending and tensile strength, total mass, and the rupture behavior of net. This is also helpful for studying the wire ring net.

These models proved fairly complete and efficient but presented noticeable limitations. It is difficult to collectively consider the factors of equivalence between calculation models and actual wire rings, including bending and tensile strength, total mass, contact with sliding friction, the flattening effect of steel wire bundles at the contact zones [15], and the rupture behavior of nets (Table 1), which affects the accuracy of the simulation results. In this context, the need for a comprehensive, numerical, nonlinear, steel-ring model that accounts for most mechanical phenomena remains to be seen.

In this article, a new nonlinear numerical model of wire rings is proposed. The model was fed by the results of fully quasi-static tension tests to correctly map the axial stress- 
TABLE 1: Comparison of mechanical models.

\begin{tabular}{lccccc}
\hline Scholars & Simulation elements & \multicolumn{3}{c}{ Factors of equivalence } \\
& & $\begin{array}{c}\text { Mechanical properties } \\
\text { during two regimes }\end{array}$ & $\begin{array}{c}\text { Total } \\
\text { mass }\end{array}$ & $\begin{array}{c}\text { Contact with } \\
\text { sliding friction }\end{array}$ & Flattening effect \\
Rupture behavior
\end{tabular}

strain curves of steel wires and the failure loads of single wire rings and of wire-ring nets. The important nonlinear physical phenomena of wire rings, such as the flattening effect, were also investigated (Section 2). This equivalent ring model accounts for the following factors of equivalence between numerical and actual wire rings: bending and tensile strength, total mass, contact with sliding friction, the flattening effect, and the rupture behavior of nets, aiming to ensure the proper description of a single ring's behavior and accurate modeling of large ring-net assemblies. These factors were reflected in a model with the material law by the input of material parameters (Section 3), and the test results of components were used to calibrate and validate the model in LS-DYNA program (Section 4). The accuracy of this approach is verified by the match between simulation and test results of a full-scale rockfall barrier prototype (Section 5).

\section{Research on Mechanical Behavior of the Wire-Ring Net}

2.1. Nonlinear Mechanical Behavior. In general, wire rings with $250-350 \mathrm{~mm}$ of internal diameter comprise a single $2.2-3 \mathrm{~mm}$ steel wire strand wrapped in $n_{\mathrm{w}}$ windings $\left(n_{\mathrm{w}}=5\right.$, $7,9,12,16$, and 19). The steel ring is generally wrapped together in two ways, namely, parallelly wrapped steel wire and twisted steel wire. The former is studied in this paper. The wire-ring net comprises an array of wire rings. According to the different types of ring-to-ring contact for wire rings, the expected loading configurations are twopoint traction, three-point traction, and four-point traction in the four-contact net pattern [16]. The complex nonlinear mechanical properties of the wire-ring net are mainly due to a production method that includes the geometric particularity of the rings, ring-to-ring contact, and the constraint patterns of the wire bundle. These nonlinear processes result in high complexity when modeling the wire-ring net, making it challenging to research.

\subsubsection{Geometric Particularity: Bending and Tension in Two} Stages. When external tensile forces are applied to a ring, combined bending and tension occur. Two stages of deformation can be identified: an initial phase (i.e., the bending stage), when bending dominates and deflections are large, and a final phase (i.e., the tensile stage), when tension dominates and deflections are small $[11,16]$. All rings have this nonlinear mechanical property, as determined by their geometric particularity.

In the bending stage, the ring first deforms elastically until the onset of plastic strain. Deformation then continues with considerable changes in the ring's shape due to plastic bending. As the ring deforms, its elastic stiffness increases, and the plastic region around the contact zone increases until a maximum curvature at the contact zone occurs. In the tensile stage, the ring is fully deformed, no extra bending forces can develop, and axial force increases rapidly. $\mathrm{Nu}-$ merous experimental studies have illustrated these features of a steel ring's behavior $[11,16]$.

\subsubsection{Ring-to-Ring Contact: Contact with Sliding Friction.} Another challenge in the numerical simulation of flexible barriers is modeling the ring-to-ring contact in a realistic geometric arrangement behavior. Upon impact, the wirering net undergoes large deformations, which means that contact occurs with sliding friction among the rings. Neglecting the true contact condition typically leads to deformation patterns that deviate from reality, affecting the force and energy distribution within the net [15]. An accurate simulation of the internal force and energy distribution is required to model net failure. However, modeling the true ring-to-ring contact is associated with high computational costs. Realistic FE modeling has become feasible with the introduction of parallel computing. Therefore, a more refined beam element discretization and true contact with the sliding friction condition can be considered [15], consequently improving the prediction of net deformation and force transmission with regard to actual tests.

\subsubsection{Constraint Patterns of Wire Bundles: Flattening Effect.} The flattening effect is also a significant challenge in the numerical simulation of the wire-ring net. Due to the constraint patterns of wire bundles, the flattening of a transverse steel-wire bundle is obvious in the contact zone, where the rings contact with and apply normal forces on each other (Figure 3(a)). Therefore, the area moment of inertia does not remain constant, resulting in decreased bending stiffness. An equivalent ring model, when considering the equivalence of axial stiffness (i.e., area $A_{0}$ of the wire bundle's cross section is equal to area $A_{\mathrm{e}}$ of a single circular cross-section beam), neglects the flattening effect at the contact zones, under two-point traction with the same 


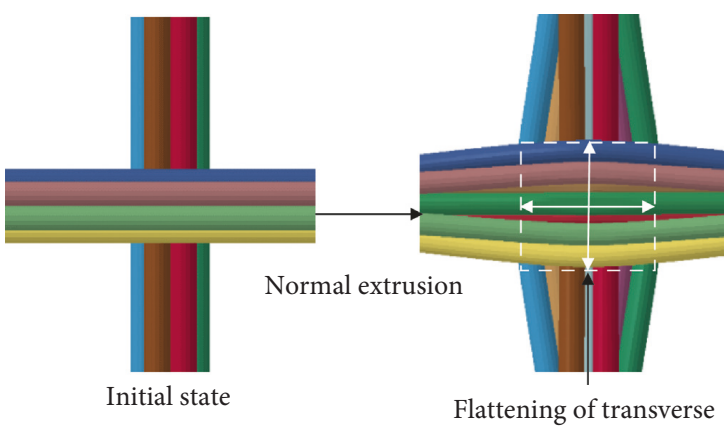

(a)

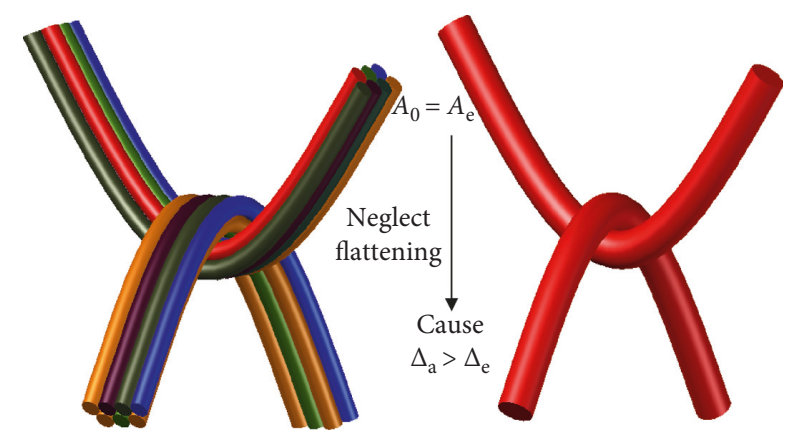

(b)

FIGURE 3: Flattening effect at the contact zone: (a) flattening phenomenon and (b) comparison of the mechanical properties.

external tensile force, and the tensile displacement response $\Delta_{\mathrm{e}}$ of the equivalent ring model is smaller than the tensile displacement response $\Delta_{\mathrm{a}}$ of the actual ring (Figure 3(b)) [15]. Therefore, the flattening effect must be considered.

2.2. Experimental Research. To develop the numerical scheme to model the wire-ring net, a series of quasi-static tensile tests were performed in the OST testing facility in Guanghan City (Sichuan, China). The tests were used to help quantify the following: (1) the axial stress-strain curves of steel wires, (2) the breaking load of single wire rings and the puncturing strength of the wire-ring nets, and (3) the affected zone length of the flattening effect. These tests also helped us to understand contact with friction.

2.2.1. Model Design. A series of experimental studies were conducted, including tensile tests on one high-strength steel wire, two-point traction tests on single wire rings, and puncturing tests on nets. As shown in Figure 4(a), the length of the one high-strength steel wire with a $3 \mathrm{~mm}$ diameter was $40 \mathrm{~cm}$. $\mathrm{R} n_{\mathrm{w}} / d_{0} / D$, for example, represents a $D \mathrm{~mm}$-diameter wire ring comprising $d_{0} \mathrm{~mm}$-diameter steel wire with $n_{\mathrm{w}}$ windings (Figure $4(\mathrm{~b})) . \mathrm{R} n_{\mathrm{w}} / d_{0} / D / W \times L$ represents a square wire-ring net of $\mathrm{R} n_{\mathrm{w}} / d_{0} / D$ at $W \mathrm{~m}$ in length $\times L \mathrm{~m}$ in width (Figure $4(\mathrm{c})$ ). Table 2 shows the parameters of the experimental models. In addition, the results of the impact tests on the wire-ring net conducted by Grassl [10] can be used as a reference.

2.2.2. Test Methods. In accordance with Metallic Materials-Tensile Testing [17], the tensile tests on single steel wires were conducted via a universal testing machine with a maximum test force of $600 \mathrm{kN}$ and with the resolution accounting for $1 / 300000$ of the maximum test force. Both ends of the steel wire were bracketed in the special fixtures of the universal testing machine. The initial gauge length $L_{0}$ clamped by the extensometer was $10 \mathrm{~cm}$. The machine pulled the steel wires at a constant velocity of $5 \mathrm{~mm} / \mathrm{min}$ (Figure 5(a)).

The tensile tests on wire rings and puncturing tests on nets were conducted via a hydraulic expanding machine. The length and width of the frame were both $3.15 \mathrm{~m}$, while the height was $3.3 \mathrm{~m}$. The maximum measurement range of the load cell and the displacement sensor was $1500 \mathrm{kN}$ and $1.5 \mathrm{~m}$, respectively. The ring specimens were connected with shackles and loaded vertically with a speed of $6.9 \mathrm{~mm} / \mathrm{s}$ until the loading force declined completely. To prevent the rings from shear failure, a $28 \mathrm{~mm}$-diameter round pin was used (Figure 5(b)). In the case of the ring tests, the strain rate was approximated by the ratio between the pin displacement and the initial length of the specimen; therefore, the strain rate was about $0.007 \mathrm{~s}^{-1}$, which can be considered quasi-static [18]. The puncturing tests comprised loading a specimen of net perpendicularly to the plane of the press, which was located at the intersection of diagonals of the net's plane. In accordance with the Steel wire ring net panels-Definitions and specifications [19], the press was formed by steel, the surface of which was smooth and the geometrical characteristics of which are marked specifically in Figure 4(c). The border rings of the net were connected to the steel frame by shackles. Then, the wire-ring net was punctured upward vertically at a speed of $6.9 \mathrm{~mm} / \mathrm{s}$ until the net failed (Figure 5(c)).

Grassl conducted impact tests on wire-ring nets [10]. The impact test frame was $4 \mathrm{~m}$ in both length and width and $5.5 \mathrm{~m}$ in height (Figure 5(d)), and the net's border rings were connected to the steel frame by shackles. A boulder with a mass of $825 \mathrm{~kg}$ was dropped from $5.5 \mathrm{~m}$ height to impact the center of the net, and accelerometers instrumented the boulder's acceleration, as established in Grassl [10].

The data from the tensile tests on the steel wires were collected under the frequency of $5 \mathrm{~Hz}$. In addition, for the safety of testers during the tension test on the wire rings and the puncturing test on the net, the data acquisition equipment and the operation desk were placed in an adjoining room. The force-displacement curve was recorded through the acquisition device, and the data from the tension tests of wire ring and the puncturing tests of nets were sampled with $100 \mathrm{~Hz}$.

\subsection{Result Analysis}

2.3.1. Steel Wires. According to the tensile tests on a single wire, the engineering stress-strain curve can be observed (Figure 6). To facilitate the establishment of the mechanical 


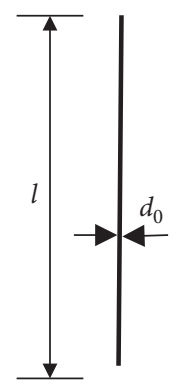

(a)

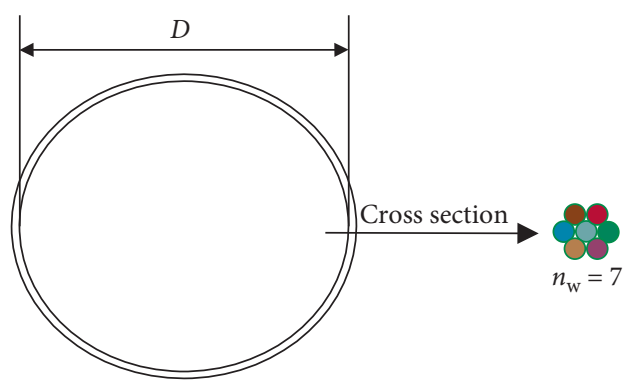

(b)

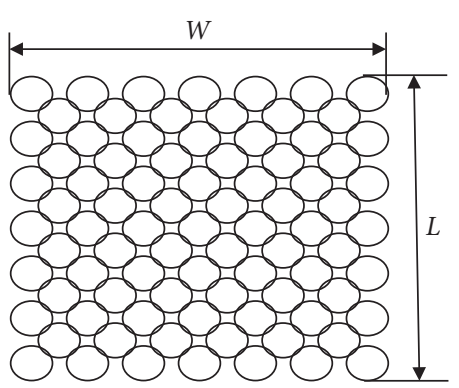

(c)

FIgURE 4: Specifications of test models. (a) Wire. (b) Wire ring. (c) Wire-ring net panel.

TABLE 2: Experimental model parameters.

\begin{tabular}{|c|c|c|c|c|c|}
\hline \multirow{2}{*}{$\begin{array}{l}\text { Tensile tests on steel wire } \\
\text { Model specifications }\end{array}$} & \multirow[b]{2}{*}{ Specimens } & \multicolumn{2}{|c|}{ Tensile tests on a single ring } & \multicolumn{2}{|c|}{ Puncturing tests on net } \\
\hline & & Model specifications & Specimens & Model specifications & Specimens \\
\hline $\begin{array}{l}l=40 \mathrm{~cm} \\
d_{0}=3 \mathrm{~mm}\end{array}$ & 2 & $\begin{array}{l}\mathrm{R} 5 / 3 / 300 \\
\mathrm{R} 7 / 3 / 300 \\
\mathrm{R} 9 / 3 / 300 \\
\mathrm{R} 12 / 3 / 300 \\
\mathrm{R} 16 / 3 / 300 \\
\mathrm{R} 19 / 3 / 300\end{array}$ & 2 & $\begin{array}{c}\mathrm{R} 5 / 3 / 300 / 3 \times 3 \mathrm{~m} \\
\mathrm{R} 7 / 3 / 300 / 3 \times 3 \\
\mathrm{R} 9 / 3 / 300 / 3 \times 3 \\
\mathrm{R} 12 / 3 / 300 / 3 \times 3 \\
\mathrm{R} 16 / 3 / 300 / 3 \times 3 \\
\mathrm{R} 19 / 3 / 300 / 3 \times 3\end{array}$ & 2 \\
\hline
\end{tabular}

model, the engineering stress-strain curve can be reduced to three stages (Figure 6): the elastic stage (0-1), hardening stage (1-2), and yield stage (2-3), which were given as point $1(0.0076,1371 \mathrm{MPa})$, point $2(0.027,1826 \mathrm{MPa})$, and point 3 $(0.046,1826 \mathrm{MPa})$, respectively. The ultimate strain and ultimate stress were obtained through the average value of each of the two tests. In addition to the material parameters mentioned above, the elastic modulus $(E=200 \mathrm{GPa})$, Poisson's ratio $(\nu=0.3)$, and material density $\left(\rho_{0}=7900\right.$ $\mathrm{kg} / \mathrm{m}^{3}$ ) were used.

2.3.2. Single Wire Rings. The force-displacement curves of wire rings (Figure 7) presented two stages in tensile deformation process of the wire rings (bending stage + tensile stage), and Figure 6 displays the breaking loads. The breaking loads of wire rings increased as the number of windings increased. With R7/3/300 test 1 , for example, the process of flattening and load force with time is shown in Figure 8 . The wire bundle clearly flattened at the contact zone between the rings and the pin. The process of flattening changed with the contact pressure: as the contact pressure increased, the wire bundle's flattening increased. After the second stage, the flattening tended to be stable.

2.3.3. Wire-Ring Nets. The measured nonlinear force-displacement curves exhibited a progressive stiffening, as well as obvious characteristics of large deformation and variable stiffness in the tension structure. According to Figure 9, the puncturing strength increased as the number of windings increased, and the breaking displacement decreased slightly as the number of windings increased, due to the increased integral rigidity of nets as the number of windings increased.
The flattening effect of the wire bundles occurred at the rings' contact zone.

To obtain the relationship between maximum tensile force (i.e., the breaking loads for wire rings and the puncturing strength for nets) and the $n_{\mathrm{w}}$ of single wire rings and wire-ring nets, the maximum tensile force (i.e., the average value of the two test results) was used as the ordinate, and $n_{\mathrm{w}}$ was used as the abscissa. Figure 10 shows their relationship. As the least square method was applied to obtain a linear curve, 22.63 is a fitting proportionality coefficient between breaking loads and $n_{\mathrm{w}}$ for wire rings, and 69.82 is a fitting proportionality coefficient between puncturing strength and $n_{\mathrm{w}}$ for nets. This provided an important basis for deducing the numerical model of wire rings.

\section{Equivalent Numerical Model}

For the numerical model's accuracy, the wire ring was modeled as an equivalent structure with a single winding and a circular cross section. The model accounted for the following equivalent factors.

3.1. Equivalence of Bending and Tensile Strength. For a steel ring of 2-point traction, in the first stage (Figure 11: O-A regime), the bending force is dominant and deflection are large, and the ring first deforms elastically until the onset of plastic strain (Figure 11: $\mathrm{O}-\mathrm{A}_{1}$ regime). $\mathrm{A}_{1}$ is the elastic limit state. The deformation of ring develops until the plastic hinge appears at the contact zones (Figure 11: $\mathrm{A}_{1}-\mathrm{A}_{2}$ regime), and $A_{2}$ is the plastic limit state. In the bending stage, the influence of the axial force is neglected. At this time, the bending moment of section $M_{2}$ is very close to the ultimate plastic moment $M_{0}$, and $M_{2}$ is supposed to be 

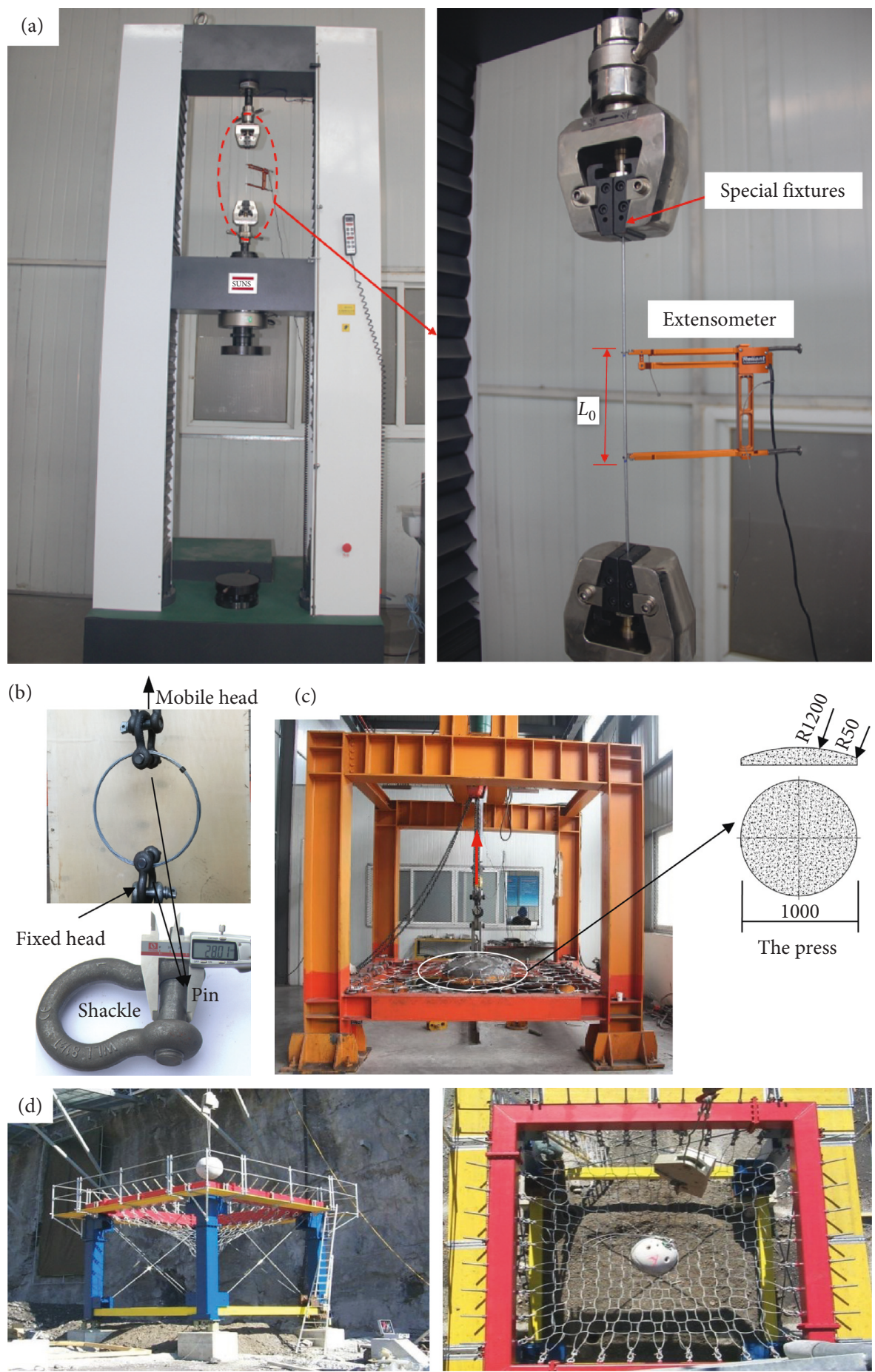

Figure 5: Loading diagram: (a) tensile tests on steel wires, (b) tensile tests on single wire rings, (c) puncturing tests on wire-ring nets, and (d) impact tests on nets $[6,10]$.

approximately equal to $M_{0}[16,20]$. Then, plastic zone continues to expand at the contact zones (Figure 11: $\mathrm{A}_{2}-\mathrm{A}$ regime). In the tensile stage (Figure 11: A-B stage), the ring is fully deformed and the plastic zone is fully matured. Bending moment decreases gradually and axial force increases rapidly, and this stage is dominated by axial force. Without regard to failure of ring, the axial force can be maximized $N_{0}$ [20].
3.1.1. Equivalence of Bending Strength. In the bending stage, the influence of the axial force is neglected. In this study, the stress-strain curve of the steel wire was reduced to three stages, where $\sigma_{1}$ is yield stress, and $\sigma_{2}$ is ultimate stress. The experimental conclusion shows the linear relationship between the maximum tensile force and $n_{\mathrm{w}}$. It is assumed that the force is evenly distributed per winding of the wire ring. In the elastic limit state, the yield moment $M_{1}$ of the wire 


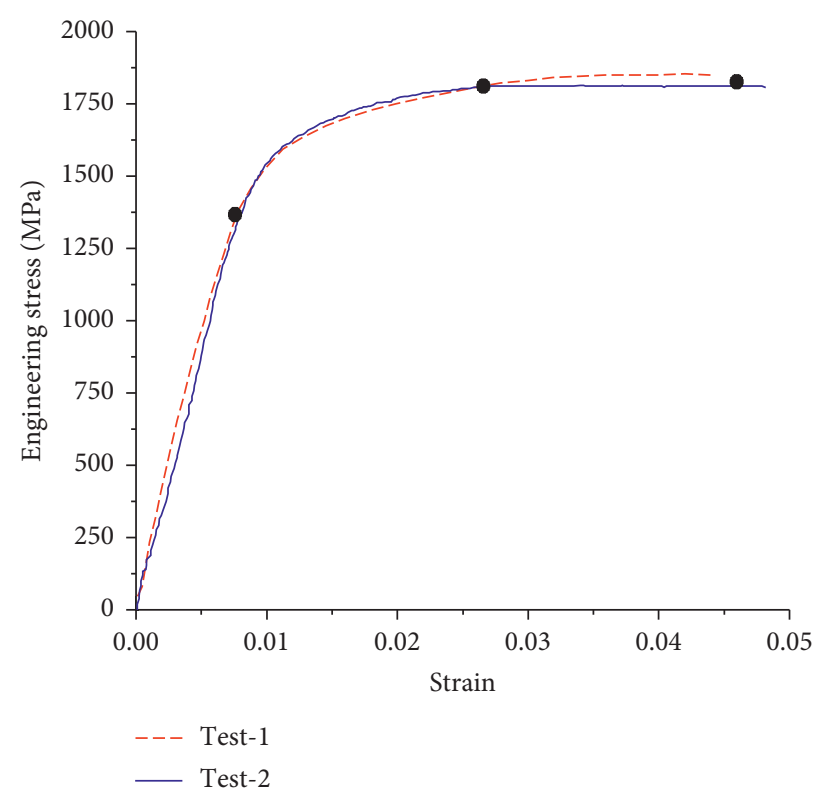

FIGURE 6: Engineering stress-strain curves of steel wires.

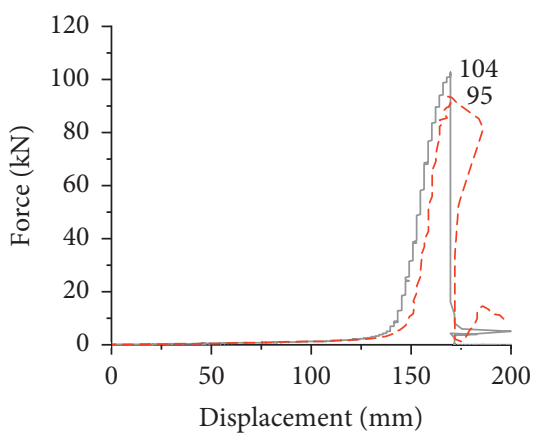

- Test-1

- - - Test-2

(a)

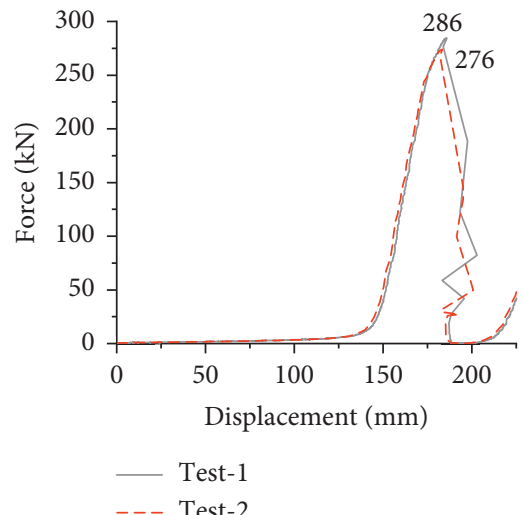

(d)

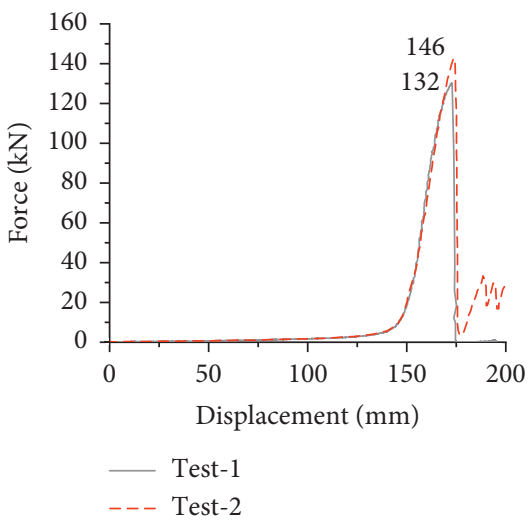

(b)

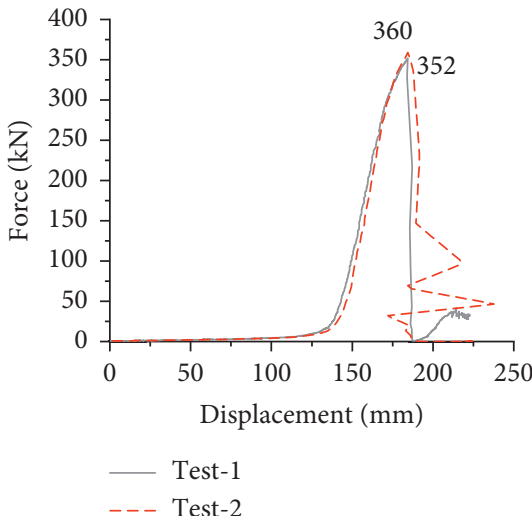

(e)

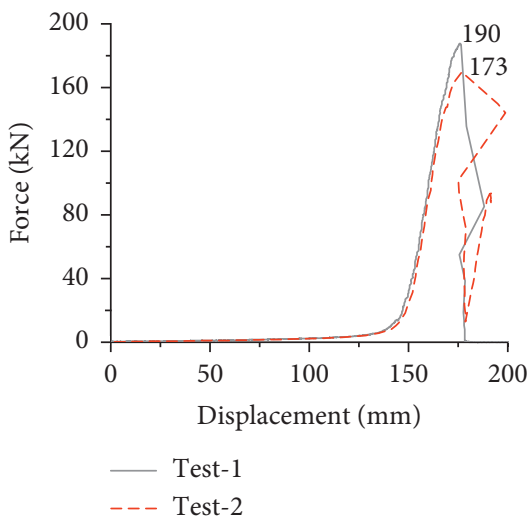

(c)

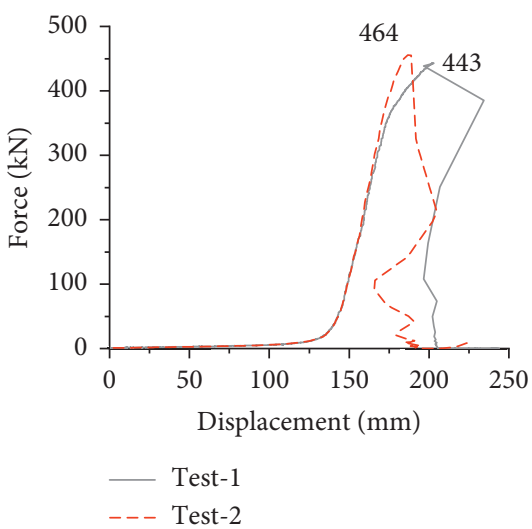

(f)

FIgURE 7: Force-displacement curves of wire rings: (a) R5; (b) R7; (c) R9; (d) R12; (e) R16; and (f) R19.

ring is equal to the sum of the yield moment $M_{1 \mathrm{~s}}$ produced by each winding (equation (1a)). In the fully plastic condition, the ultimate plastic moment $M_{2}$ of the wire ring is equal to the sum of the ultimate plastic moment $M_{2 \mathrm{~s}}$ produced by each steel-wire winding (equation (1b)) [21]. In the two-point traction of the wire ring, the applied external 


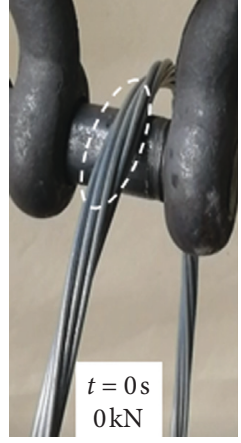

(a)

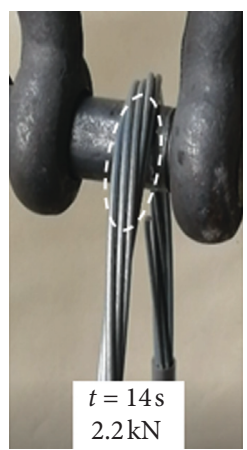

(b)

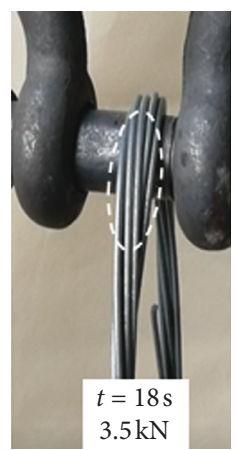

(c)

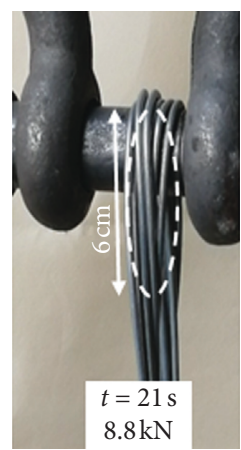

(d)

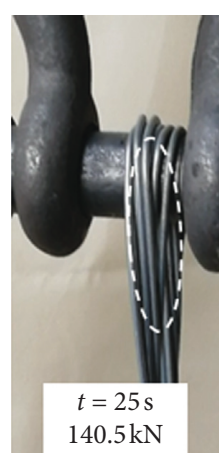

(e)

FIGURE 8: Development process of the flattening effect.

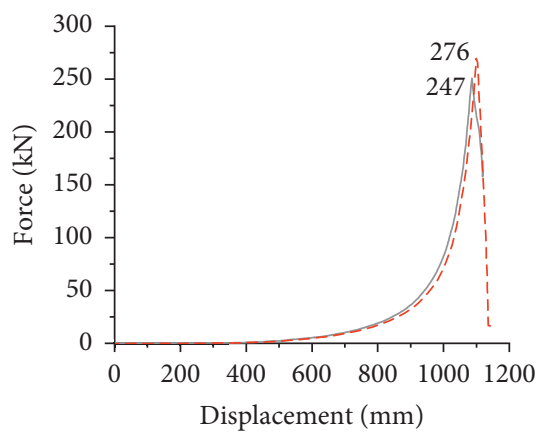

- Test-1

--- Test-2

(a)

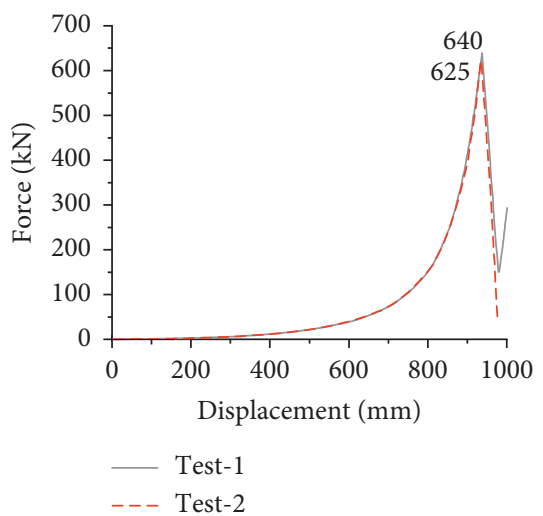

(d)

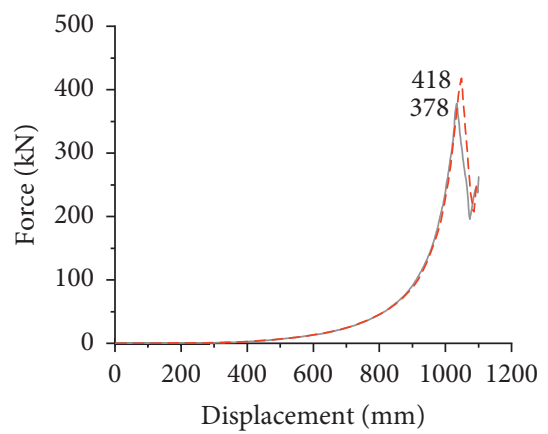

- Test-1

- - - Test-2

(b)

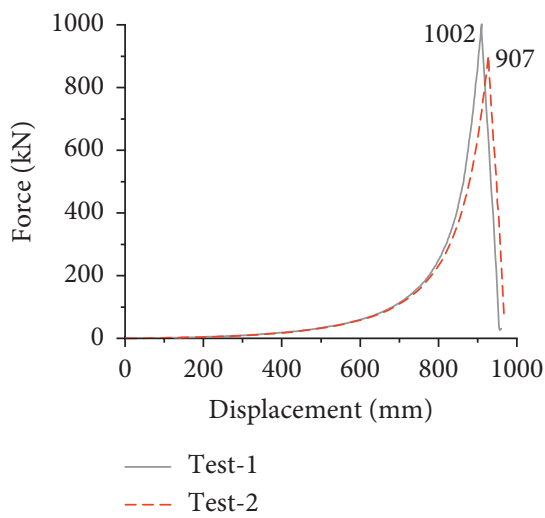

(e)

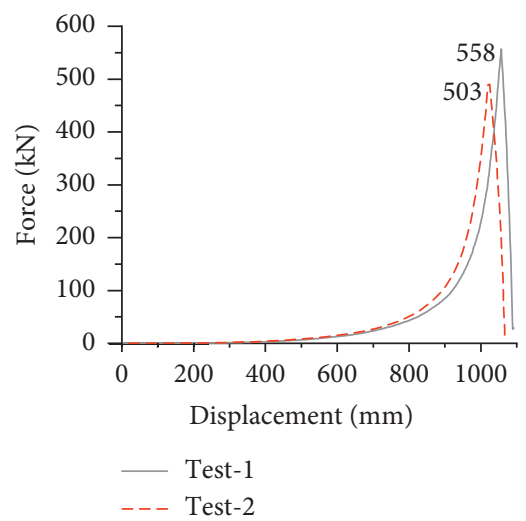

(c)

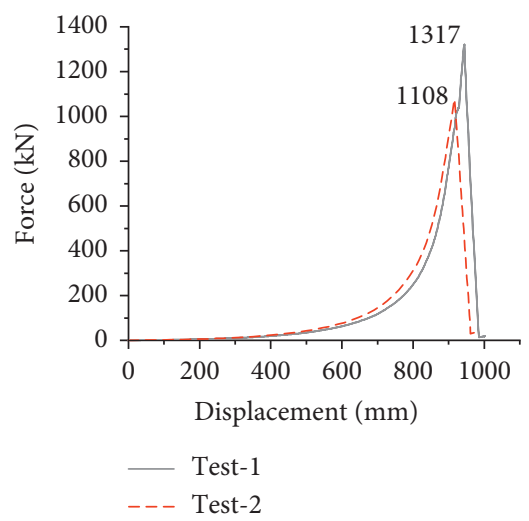

(f)

FiguRE 9: Force-displacement curves of wire-ring nets: (a) R5; (b) R7; (c) R9; (d) R12; (e) R16; and (f) R19.

force that allows the internal force of the actual wire ring at the contact zones to reach $M_{1}$ or $M_{2}$ should also allow the contact zones of the equivalent wire ring to reach the corresponding bending strength $M_{1 \mathrm{e}}$ or $M_{2 \mathrm{e}}$. According to the solution of equations (1a) and (1b), the relationship between the diameter $d_{\mathrm{e}}$ of the equivalent wire ring and the steel-wire diameter $d_{0}$ can be obtained via equation (2):

$$
\begin{aligned}
& M_{1}=n_{\mathrm{w}} M_{1 \mathrm{~s}}=n_{\mathrm{w}}\left(\frac{\pi \sigma_{1} d_{0}^{3}}{32}\right)=M_{1 \mathrm{e}}=\frac{\pi \sigma_{1} d_{\mathrm{e}}^{3}}{32}, \\
& M_{2}=n_{\mathrm{w}} M_{2 \mathrm{~s}}=n_{\mathrm{w}}\left(\frac{\sigma_{2} d_{0}^{3}}{6}\right)=M_{2 \mathrm{e}}=\frac{\sigma_{2} d_{\mathrm{e}}^{3}}{6}, \\
& d_{\mathrm{e}}=\sqrt[3]{n_{\mathrm{w}}} d_{0} .
\end{aligned}
$$




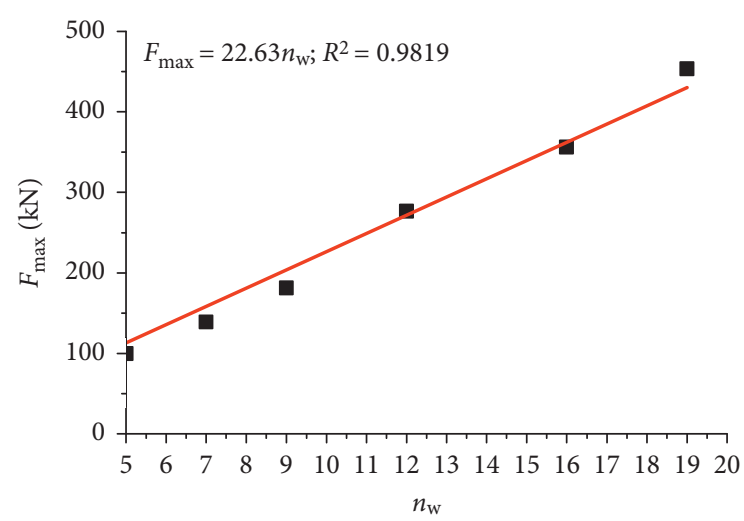

(a)

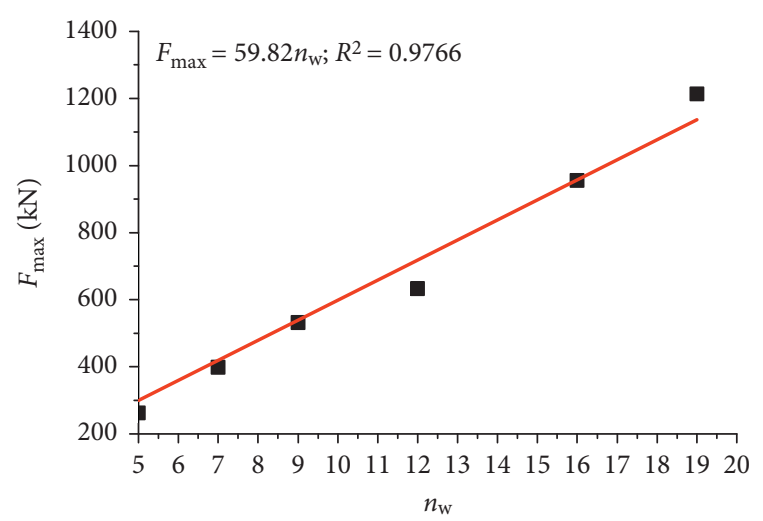

(b)

FIGURE 10: Relationship between maximum tensile force and $n_{\mathrm{w}}$ : (a) single wire ring and (b) wire-ring net.

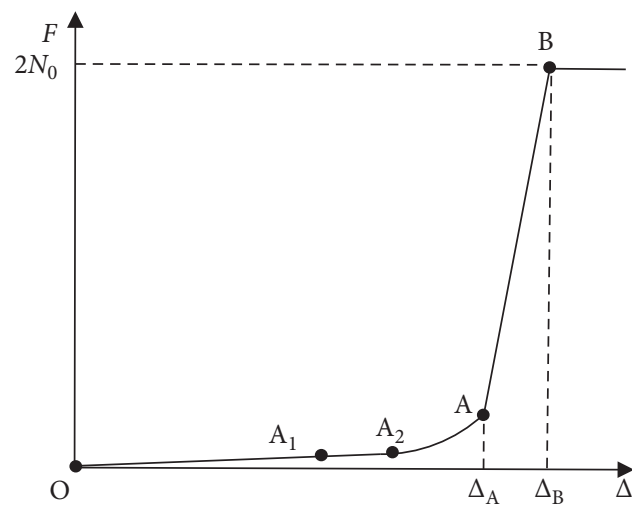

(a)

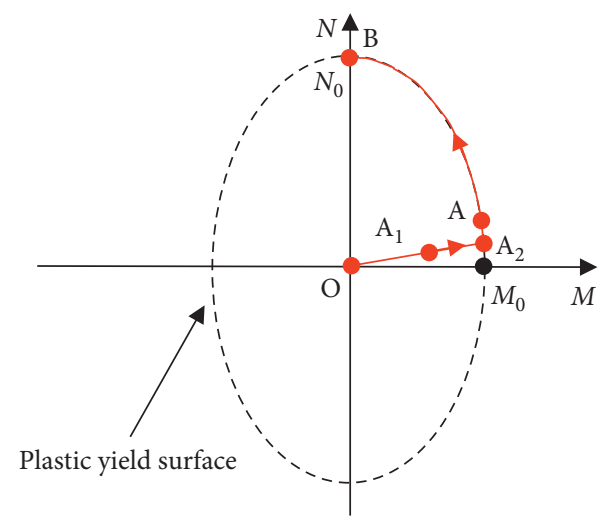

(b)

FIgURE 11: 2-Point traction of the ring: (a) tensile force-displacement curve and (b) limit of bending moment-axial force interaction.

3.1.2. Equivalence of Tensile Strength. In the tensile stage, the influence of the bending moment is ignored, assuming that the wire can achieve ultimate axial force. The ultimate axial force $N_{0}$ of the actual wire ring and the ultimate axial force $N_{0 \mathrm{e}}$ of the equivalent wire ring can be calculated as equations (3a) and (3b), respectively:

$$
\begin{aligned}
& N_{0}=2 n_{\mathrm{w}} \sigma_{2}\left(\frac{\pi d_{0}^{2}}{4}\right), \\
& N_{0 \mathrm{e}}=2 \sigma_{2}\left(\frac{\pi d_{\mathrm{e}}^{2}}{4}\right)=2 n_{\mathrm{w}}^{2 / 3} \sigma_{2} \frac{\pi d_{0}^{2}}{4},
\end{aligned}
$$

when $n_{\mathrm{w}}>1$, then $N_{0}>N_{0 \mathrm{e}}$. Obviously, the two equivalent control equations (equation $(1 \mathrm{a})=$ equation $(1 \mathrm{~b})$ and equation (3a) = equation (3b)) cannot be satisfied simultaneously. Therefore, $\sigma_{2}$ needs be increased to $\sigma_{\mathrm{u}}$ to achieve the equality between equations (3a) and (3b). After adjustment, the ultimate axial force $N_{0}=N_{0 \text { eu }}$ :

$$
N_{0}=2 n_{\mathrm{w}} \sigma_{2}\left(\frac{\pi d_{0}^{2}}{4}\right)=N_{0 \mathrm{eu}}=2 \sigma_{\mathrm{u}}\left(\frac{\pi d_{\mathrm{e}}^{2}}{4}\right)=2 n_{\mathrm{w}}^{2 / 3} \sigma_{\mathrm{u}}\left(\frac{\pi d_{0}^{2}}{4}\right)
$$

where $N_{\text {0eu }}$ is the ultimate axial force of the equivalent wire ring after adjustment.

The adjusted ultimate stress $\sigma_{\mathrm{u}}$ can be deduced as follows:

$$
\sigma_{\mathrm{u}}=\sqrt[3]{n_{\mathrm{w}}} \sigma_{2}
$$

By using the abovementioned equivalent method, bending strength is equivalent between the actual wire ring and the equivalent wire ring, respectively, and tensile strength is also equivalent between the actual wire ring and the equivalent wire ring.

3.2. Equivalence of Mass. According to equation (2), the cross-sectional area $A_{\mathrm{e}}$ of the numerical wire ring is smaller than the cross-sectional area $A_{0}$ of the actual wire ring, leading to the decreased mass of the numerical wire ring, which will affect the transmission of shock waves and the system's inertial response if the net encounters the mass's direct impact [22]. Therefore, the mechanical model must be amended to make up for the decrease in mass in accordance with the principle of mass conservation. Nicot et al. [11] and Grassl [10] introduced the mass nodes, and the mass 
distribution of these models is not uniform. In this study, the mass of the wire ring was distributed in a more realistic way:

$$
m_{0}=n_{\mathrm{w}} \rho_{0} A_{0} l_{0}=m_{\mathrm{e}}=\rho_{\mathrm{e}} A_{\mathrm{e}} l_{0},
$$

where $m_{0}$ is the mass of the actual wire ring, $m_{\mathrm{e}}$ is the mass of the equivalent wire ring, $\rho_{0}$ is the density of the actual material, and $\rho_{\mathrm{e}}$ is the material density of the equivalent wire ring.

Combining equations (2) and (6) obtains

$$
\rho_{\mathrm{e}}=\sqrt[3]{n_{\mathrm{w}}} \rho_{0} .
$$

3.3. Contact with Sliding Friction. In LS-DYNA, the general contact model was included to deal with ring-to-ring contact-sliding friction. Contact forces were applied to the contacted beam elements, including normal and tangential contact forces. The contact model is shown Figure 12.

The normal contact force $f_{\mathrm{n}}$ can be expressed as [23]

$$
f_{\mathrm{n}}=k|\delta|
$$

where $\delta$ is the overlap, $k=(1 / 2) f_{\mathrm{s}}\left(m_{1} m_{2} /\left(m_{1}+\right.\right.$ $\left.\left.m_{2}\right)\right)\left(1 / \Delta t_{\mathrm{n}}\right)^{2}$ is the interface stiffness, $f_{\mathrm{s}}$ is the penalty stiffness factor, $m_{1}$ and $m_{2}$ are the mass of the master segment and slave segment, respectively, and $\Delta t_{\mathrm{n}}$ is the current time step [23].

Tangential contact force $f_{\mathrm{t}}$ in LS-DYNA is based on a Coulomb formulation. Let $\mu$ be the coefficient of friction, $\Delta s$ the relative tangential displacement, and $f_{\mathrm{t}}$ the tangential contact force. The frictional algorithm, outlined below, uses the equivalent of an elastic plastic spring. The calculation is as follows [23]:

$$
f_{\mathrm{t}}= \begin{cases}k|\Delta s| ; & \text { if } k|\Delta s| \leq \mu f_{\mathrm{n}}, \\ \mu f_{\mathrm{n}} ; & \text { otherwise. }\end{cases}
$$

3.4. Flattening Effect. The tests' phenomena (Figure 8) show that by the flattening effect each influence length $l_{z}$ of two adjoining rings is $12 \mathrm{~cm}$, which is $1 / 8$ of the circumference $l$ of the wire ring. To create a numerical model, the contact length of the bundles at each contact zone was hypothetically defined as $l_{z}$. For the inner rings, the total contact length was $4 l_{z}$. Figure 13 shows the schematic of contact zones in the net.

3.4.1. Contact Zone. The bending stage basically completed the flattening of steel wire bundles at the contact zones (Figure 7), and it is assumed that the flattened steel wires were arranged parallelly. Thus, the bending stiffness $k_{I A}$ of the steel-wire bundles was assumed to be equal to the sum of the bending stiffness per winding of the wire ring:

$$
k_{I A}=\sum E I_{i}=n_{\mathrm{w}} \sum E I=n_{\mathrm{w}} E\left(\frac{\pi d_{0}^{4}}{64}\right) \text {. }
$$

The bending stiffness $k_{I E}$ of the contact zones of the equivalent numerical wire ring can be expressed as follows:

$$
k_{I E}=E_{\mathrm{e}} I_{\mathrm{e}}=E_{\mathrm{e}}\left(\frac{\pi d_{\mathrm{e}}^{4}}{64}\right) \text {, }
$$

where $E_{\mathrm{e}}$ is the equivalent elastic modulus of contact zones, and $I_{\mathrm{e}}$ is the equivalent area moment of inertia.

When $k_{I A}=k_{I E}$, the following equation can be obtained:

$$
E_{\mathrm{e}}=\frac{E}{\sqrt[3]{n_{\mathrm{w}}}}
$$

3.4.2. Noncontact Zone. The elastic modulus of the equivalent wire ring at the noncontact zones was defined as $E$, mainly considering the coordination of axial stiffness and bending stiffness at the noncontact zones. Axial stiffness $k_{N A}$ of the actual wire ring at the noncontact zones can be expressed as follows:

$$
k_{N A}=\sum E A_{0}=E\left(\frac{\pi d_{0}^{2}}{4}\right) n_{\mathrm{w}} .
$$

Axial stiffness $k_{N E}$ of the equivalent numerical wire ring at the noncontact zones can be expressed as follows:

$$
k_{N E}=E A_{\mathrm{e}}=n_{\mathrm{w}}^{2 / 3} E\left(\frac{\pi d_{0}^{2}}{4}\right) .
$$

Apparently, $k_{N E}<k_{N A}$, which can qualitatively compensate for the increased displacement caused by the flattening effect [15].

3.5. Rupture Behavior. In this paper, the piecewise linear plasticity model was used, based on the Mises yield criterion independent of hydrostatic pressure. For the yield stress of high-strength steel greater than $1800 \mathrm{MPa}$, these alloys only exhibit a $4.8 \%$ increase in yield stress when strain rates increase from quasi-static to $200 \mathrm{~s}^{-1}$ [24]. Based on these observations, in the case of high-strength steel wire, small changes in the flow constitutive curve could be ignored in the dynamic finite element model of this paper. Numerical calculations generally use the plastic strain of elements to conduct failure control [25].

As mentioned above, once the maximum plastic hinge moment of the wire ring is reached, the plastic strain at this time is located near the right of point 2 (Figure 14). To simplify the calculation, point 2 is regarded as the starting point of the stress adjustment (Figure 14). The feasibility was proven by later verification calculations.

As shown in Figure 14, the effective stress-plastic strain of elements was developed in line with the path $0-1-2-3^{\prime}$ at the noncontact zones, and with path $0^{\prime}-1-2-3^{\prime}$ at the contact zones. If the plastic strain at failure is set to be the material's actual plastic strain at failure $\varepsilon_{y}^{3}$, then the failure of elements will occur in advance $[15,25]$. Thus, the plastic stage must be lengthened, the ultimate plastic strain must be adjusted to $\varepsilon_{\mathrm{u}}$, and the model's new constitutive curve must be $0-1-2-3^{\prime}-4^{\prime}$ for noncontact zones and $0^{\prime}-1-2-3^{\prime}-4^{\prime}$ for contact zones.

In the newly adjusted constitutive curve, among material parameters, the elastic modulus $E$, yield stress $\sigma_{1}$, and actual ultimate stress $\sigma_{2}$ are known parameters; furthermore, $\sigma_{\mathrm{u}}$ 


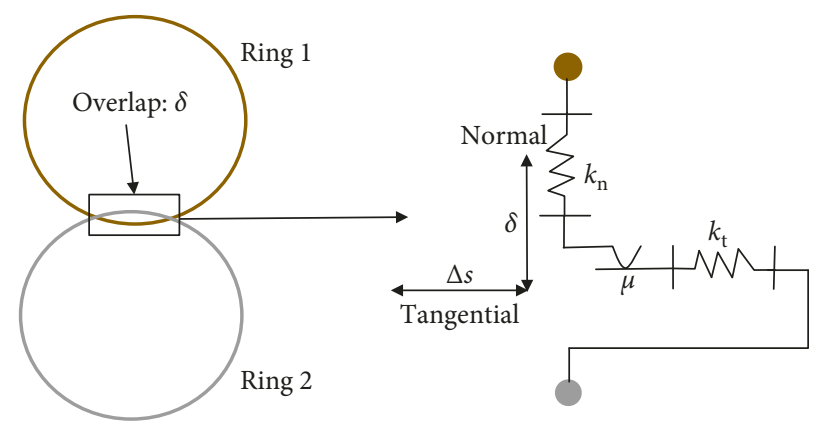

Figure 12: Contact with sliding friction model.

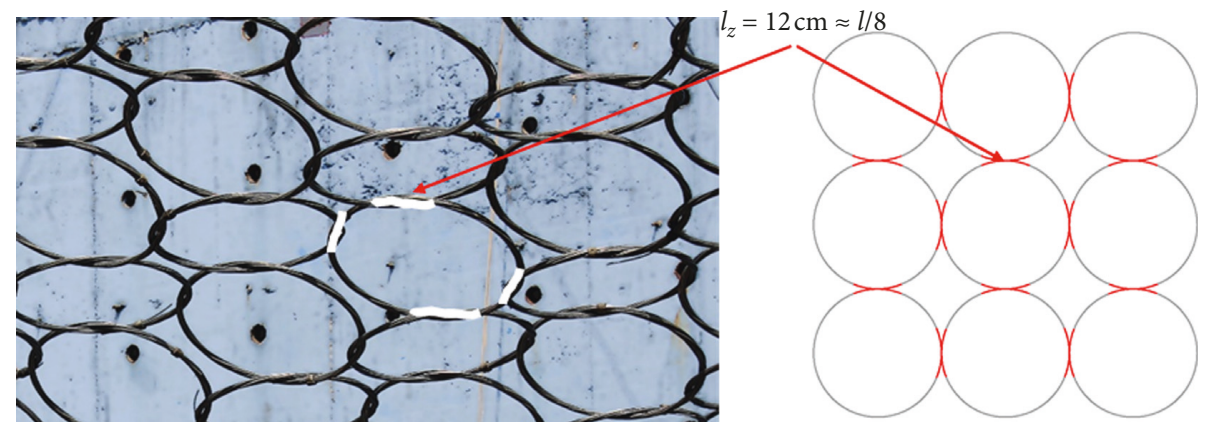

Figure 13: Schematic of contact zones.

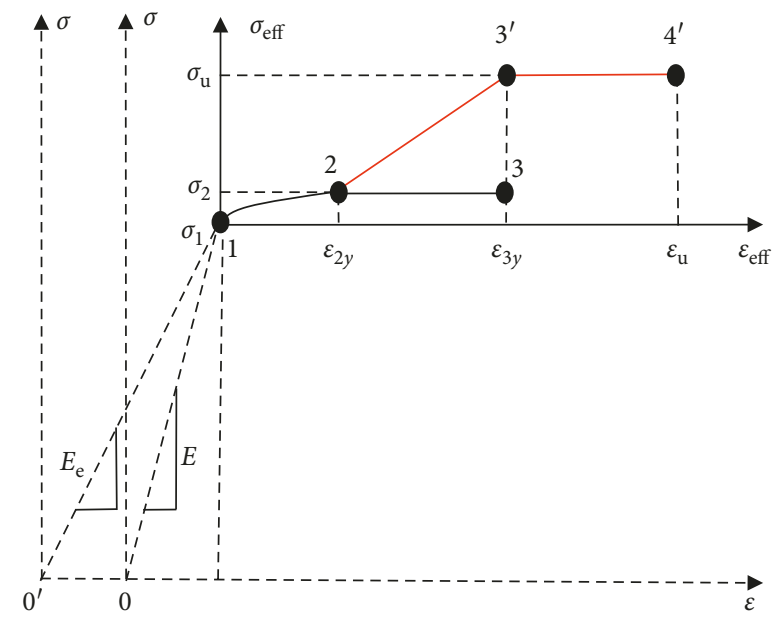

FIgURE 14: Effective stress-plastic strain curve.

and $E_{\mathrm{e}}$ can be obtained through the equivalent calculation, and $\varepsilon_{\mathrm{u}}$ can be obtained by inverse formulation with the objective function (equation (15)):

$$
W=\frac{F_{\mathrm{u}}}{F_{\max }},
$$

where $F_{\mathrm{u}}$ is the maximum tensile force of the numerical calculation, and $F_{\max }$ is the maximum tensile force of the tests. When the objective function value $W=1, \varepsilon_{\mathrm{u}}$ is the optimal solution.

Table 3 specifies the basic material parameters of a comprehensive numerical model, and only the ultimate plastic strain must be determined through the inverse formulation. The increased density $\rho_{\mathrm{e}}$ of the equivalent ring leads to an increased time step [23], contributing to the improved calculation efficiency. All dominant equivalent factors were thus reflected in a comprehensive numerical model with the nonlinear material law by the input of material parameters.

\section{Calibration and Verification of the Numerical Model}

LS-DYNA is so effective at geometric nonlinearity, material nonlinearity, and contact nonlinear analysis that it can accurately simulate various nonlinear behaviors. In this paper, LS-DYNA software is employed to simulate the whole process of test.

4.1. Tensile Tests on Single Wire Rings. Theoretically, the equivalent wire ring discretized by straight beams can better simulate the actual wire ring when the number of straight beams increases, and the calculation results can be more reliable, but at more computational cost. Based on this, the optimized number of discretized elements must be defined. Taking R7/3/300 as an example, the discretized element numbers $n$ of the wire ring are 16,32,64, 128, and 256. As the number of discretized elements increases, the deformation and the plastic hinge of the contact zones develop more fully, and the simulation's force-displacement curve is closer to the test curve (Figure 15).

When a wire ring is discretized by 256 beam elements, Figure 16 shows the evolution of the ring deformation of R7/ 
TABLE 3: Basic material parameters.

\begin{tabular}{|c|c|c|c|c|c|c|c|c|c|}
\hline$d_{\mathrm{e}}$ & $\rho_{\mathrm{e}}$ & $v$ & $\sigma_{1}$ & $\sigma_{2}$ & $\varepsilon_{2 y}$ & $\varepsilon_{3 y}$ & $\sigma_{\mathrm{u}}$ & $E_{\mathrm{e}}$ & $\varepsilon_{\mathrm{u}}$ \\
\hline$\sqrt[3]{n_{\mathrm{w}}} d_{0}$ & $\sqrt[3]{n_{\mathrm{w}}} \rho_{0}$ & 0.3 & $1371 \mathrm{MPa}$ & $1826 \mathrm{MPa}$ & 0.018 & 0.038 & $\sqrt[3]{n_{\mathrm{w}}} \sigma_{2}$ & Noncontact zones $E$ Contact zones $E / \sqrt[3]{n_{\mathrm{w}}}$ & Inverse formulation \\
\hline
\end{tabular}

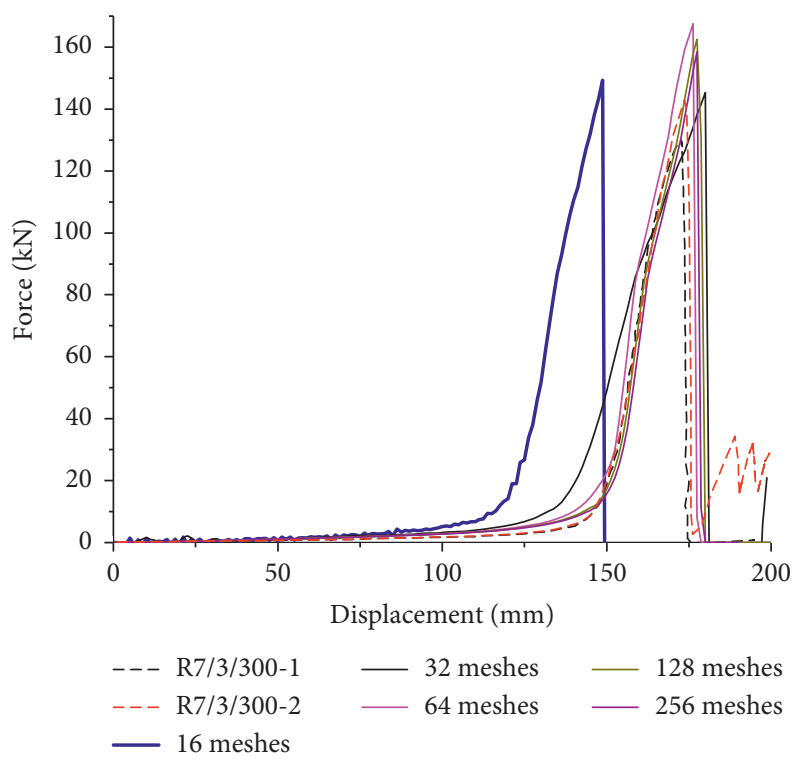

FIgURE 15: Force-displacement curves for different numbers of discretized elements (R7/3/300).

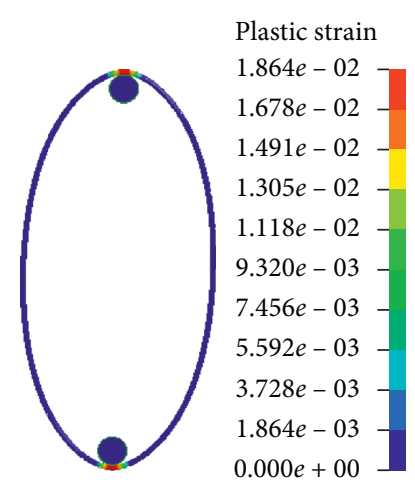

(a)

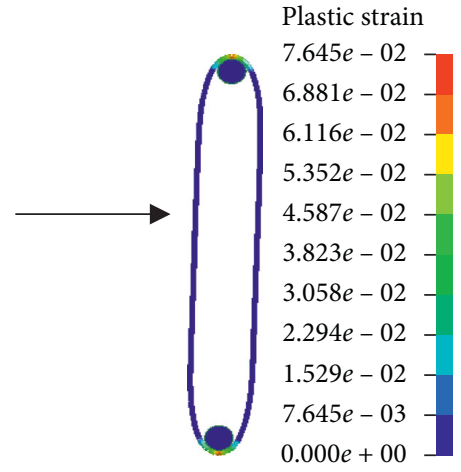

(b)

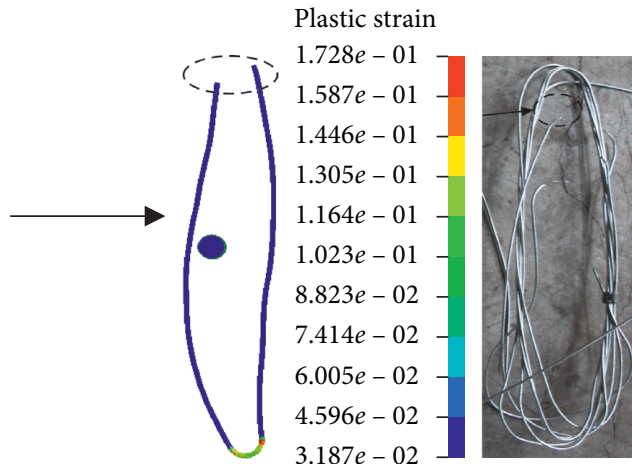

(c)

FIGURE 16: Deformation and contours of equivalent plastic strain: (a) initiation of plasticity, (b) plastic localization for $86 \%$ of the total elongation, and (c) rupture (R7).

3/300 at different stages. The behavior that occurred from the initial configuration to the initiation of plastic behavior in Figure 16(a) is described by the elastic bending and stretching properties of the wire ring. In addition, Figure 16(b) shows that the plastic region around the contact zone increased as the test progressed. The ring bent until a maximum curvature at the contact zone occurred, and the final failure positions occurred at the contact zone, consistent with the test (Figure 16(c)), which shows that the actual rupture behavior of the wire ring can be simulated by the failure criterion based on the effective plastic strain.

Figure 17 shows the comparison of force-displacement curves between the tests and simulations (for R12, R16, and R19). The simulation and test curves match well, which verifies that the mechanical model in this paper can be employed to replicate single wire rings. To illustrate the necessity of considering the flattening effect, a model result without the flattening effect is shown in the SF curve in Figure 17. Figure 17 also shows that the stiffness softening effect after contact flattening was not considered, resulting in increased stiffness during the bending and stretching stage of the wire ring and advanced breaking displacement. This is consistent with the literature [15] and proves the necessity of considering the flattening effect.

4.2. Puncturing Tests on Nets. A refined model with many discretized elements can accurately simulate the mechanical 


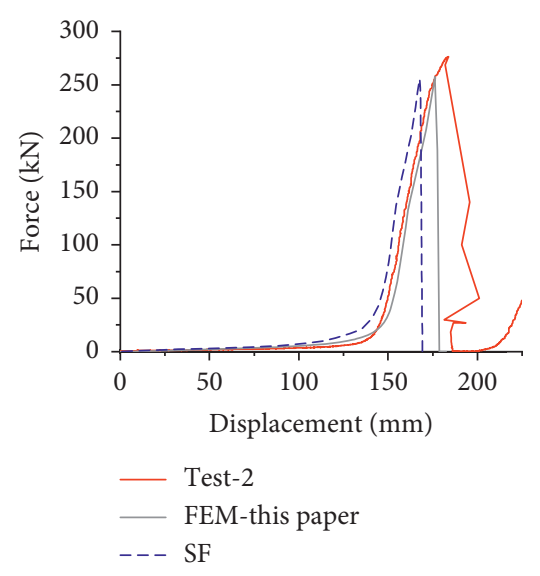

(a)

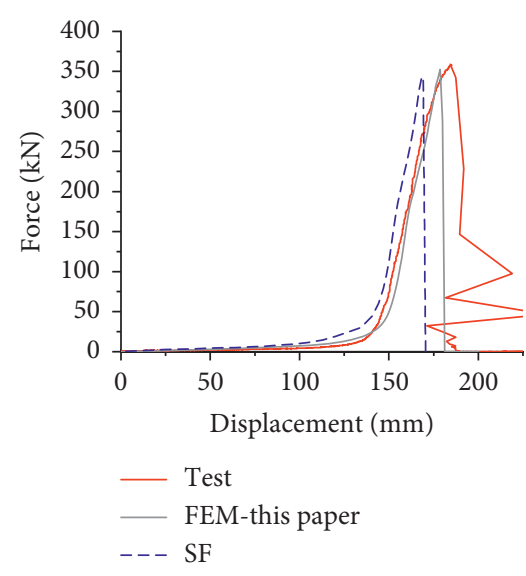

(b)

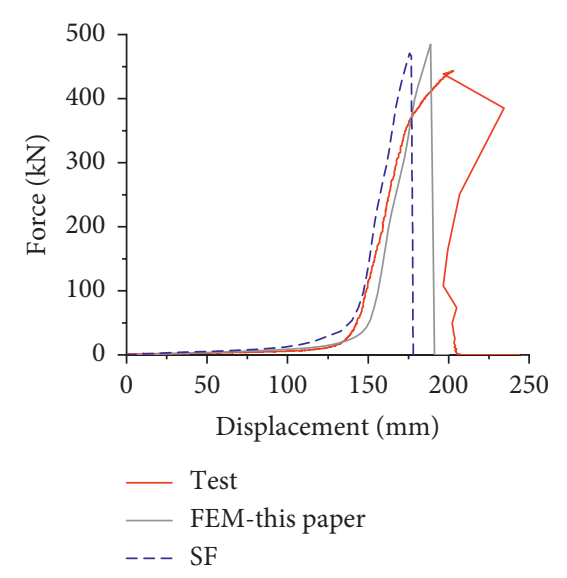

(c)

FIGURE 17: Force-displacement curve comparisons of single wire rings between tests and simulations: (a) R12, (b) R16, and (c) R19.

behavior of wire rings, but at a high computational cost. More attention should be paid to the energy consumption and deformation capacity of the net during the calculation. Figure 15 shows that the simulation and test curves matched well when the wire ring was discretized by 32 elements. Therefore, when researching the whole wire-ring net, the wire rings were initially discretized by 32 elements, and R7/ $3 / 300$, an example from the puncturing test, was analyzed. The net was initially in a relaxed state.

With the development of loading, the rings had a relative slip and gradually tended to tension (Figure 18(a)). After further loading, the rings began to deform (Figure 18(b)). The net's failure position occurred at the net's contact position and the press's edge. Ultimately, the failure phenomenon of the simulation shows good agreement with the test (Figure 18(c)).

The effective plastic strain at failure obtained by inverse formulation will not be elaborated here. According to the force-displacement curves depicted in Figure 19, the test and simulation curves were well matched, and little disparity existed regarding peak displacement. To illustrate the necessity of considering the flattening effect, a model result without the flattening effect is shown in the SF curve in Figure 19. Figure 19 shows that the stiffness softening effect after contact flattening was not considered, resulting in increased stiffness during the bending and stretching stage of the nets and advanced breaking displacement.

Furthermore, from the perspective of peak displacement, the test and simulation results of this study were very close, with a maximum error of $4.8 \%$ for R7, and the test and simulation results without the flattening effect were different, with a maximum error of $8.0 \%$ for R7 (Table 4 ), meaning that the adjustive material parameters, the failure criteria, and the discretized element numbers of wire rings were effective when simulating the mechanical behavior of the wire-ring net.

4.3. Impact Tests on Nets. In 2002, experimental impact test series of wire-ring nets were conducted. The tests on the net directly fixed to the frame were performed at lower kinetic impact energies (between $24 \mathrm{~kJ}$ and $48 \mathrm{~kJ}$ ). These series of experiments were conducted using an $825 \mathrm{~kg}$ spherical concrete impactor instrumented with eight accelerometers $[6,10]$. In this study, the first series of the low energy tests of $45 \mathrm{~kJ}$ is analyzed (see Figure 5(d)). The integral parts of the data acquisition system are a microcontroller and a 12-bit A-D transformer. This deceleration is tracked with eight capacity accelerometers. The range of the sensors is $50 \mathrm{~g}$ with guaranteed overload of maximum $1000 \mathrm{~g}$. A special integration procedure has been developed to obtain the velocity and position of the rock [6].

To verify the accuracy of the numerical equivalent model, an impact model on net was established. The material parameters of steel wire refer to [6], and the stress-strain curve of the material was adjusted according to this paper's method (Table 5). The ring-to-ring friction coefficient for the impact test was 0.15. The impactor-ring net friction was 0.25 . To account for the net's initial sag due to gravity, a pretest gravity step was included, and to avoid the dynamic effects at this step, gravity was increased smoothly from zero to $9.81 \mathrm{~m} / \mathrm{s}^{2}$.

Figure 20 shows that the test and simulation curves almost coincided with each other. Before the boulder reached maximum impact displacement, the test curve had a good match with that of the simulation, but the simulation curve differed from the test from the moment of the boulder's rebound. This is because the wire rings' elastic modulus at the contact zones was reduced during the simulation, resulting in an increase in the net's elastic internal energy when the boulder reached maximum displacement, and the boulder's rebound in the simulation increased. Since Grassl [10] did not take into account the ring-to-ring contact with sliding friction and the flattening effect at contact zones, a gap occurs with the experimental data.

Figure 21(a) shows the simulated deformation of the wire-ring net during a $5.5 \mathrm{~m}$ rockfall test. For the sake of clarity, the rigid frame is not shown. Figure 21(b) shows the evolution of kinetic energy and potential energy. In 


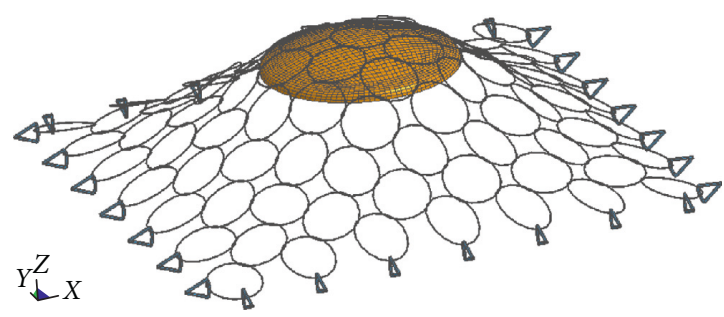

(a)

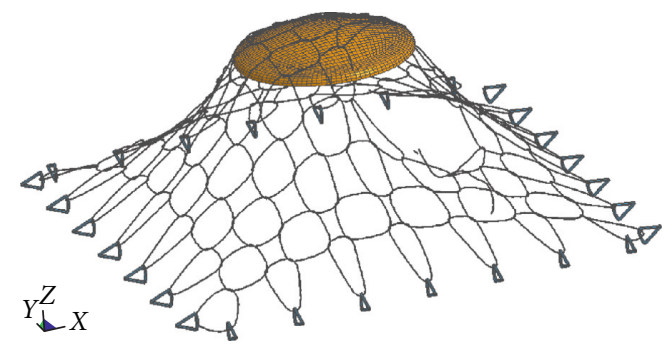

(c)

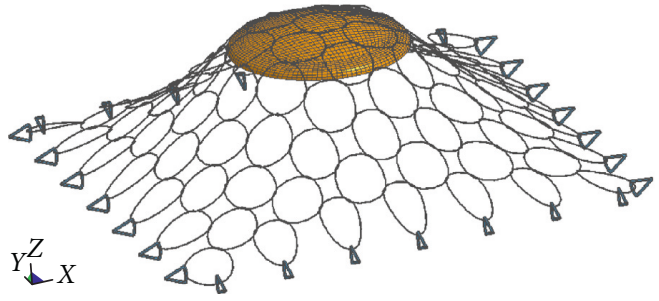

(b)

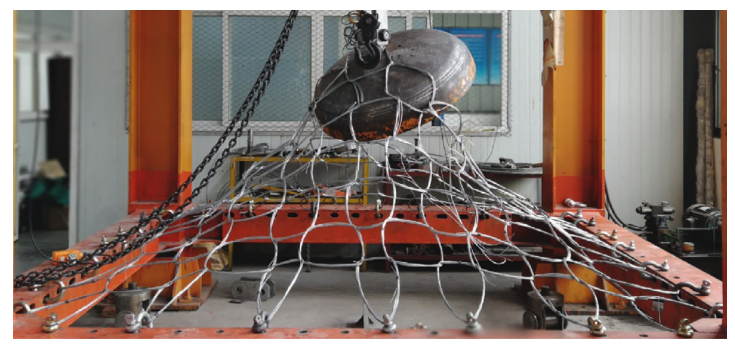

(d)

FIGURE 18: Deformation process of the wire-ring net (R7).

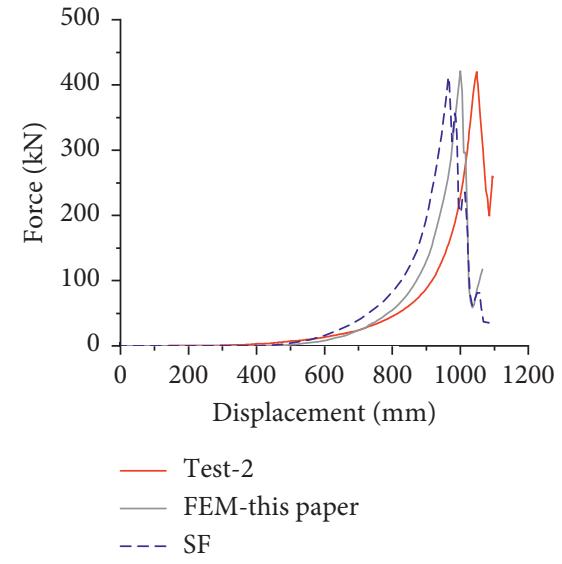

(a)

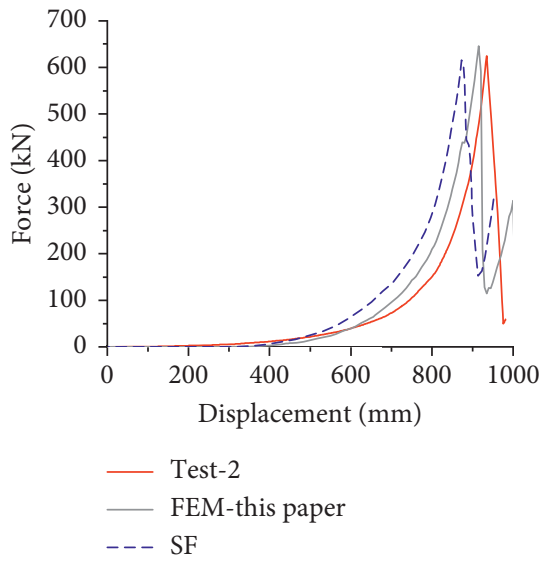

(b)

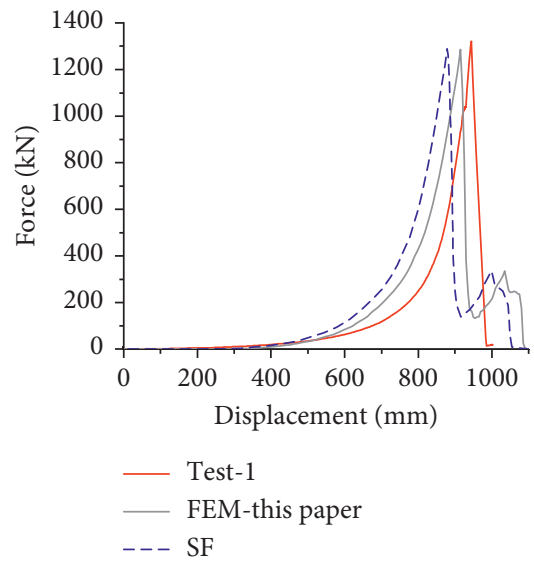

(c)

Figure 19: Force-displacement curve comparisons of nets between tests and simulations: (a) R7, (b) R12, and (c) R19.

TABLE 4: Key data comparison of puncturing test.

\begin{tabular}{|c|c|c|c|}
\hline \multirow{2}{*}{ Specimens } & & \multicolumn{2}{|c|}{ Peak displacement } \\
\hline & & Absolute values $(\mathrm{mm})$ & Error $(\%)$ \\
\hline \multirow{3}{*}{ R7 } & Test 2 & 1047.6 & \\
\hline & FEM-this paper & 998.5 & 4.8 \\
\hline & SF & 964.3 & 8.0 \\
\hline \multirow{3}{*}{$\mathrm{R} 12$} & Test 2 & 935.6 & \\
\hline & FEM-this paper & 913.6 & 2.4 \\
\hline & SF & 879.1 & 7.1 \\
\hline \multirow{3}{*}{ R19 } & Test 1 & 946.3 & \\
\hline & FEM-this paper & 915.3 & 3.3 \\
\hline & $\mathrm{SF}^{1}$ & 875.5 & 7.5 \\
\hline
\end{tabular}

Note. These peak displacements occurred when the force reached its maximum.

the initial stage of impact, the kinetic energy and potential energy of the boulder gradually decrease. When the rockfall reaches the lowest point, the potential energy and kinetic energy become $0 \mathrm{~kJ}$, and the net consumes the most energy. The final energy consumption of the net is $20 \mathrm{~kJ}$. 
TABle 5: Material parameters of the impact test on nets.

\begin{tabular}{|c|c|c|c|c|c|c|c|c|}
\hline$d_{\mathrm{e}}$ & $\rho_{\mathrm{e}}$ & $v$ & $\sigma_{1}$ & $\sigma_{2}$ & $\varepsilon_{y}^{2}$ & $\varepsilon_{y}^{3}$ & $\sigma_{\mathrm{u}}$ & $E_{\mathrm{e}}$ \\
\hline $5.74 \mathrm{~mm}$ & $15016 \mathrm{Kg} / \mathrm{m}^{3}$ & 0.3 & $1840 \mathrm{MPa}$ & $1840 \mathrm{MPa}$ & 0.01 & 0.015 & $3580 \mathrm{MPa}$ & Noncontact zones $200 \mathrm{Gpa}$ Contact zones $105 \mathrm{Gpa}$ \\
\hline
\end{tabular}

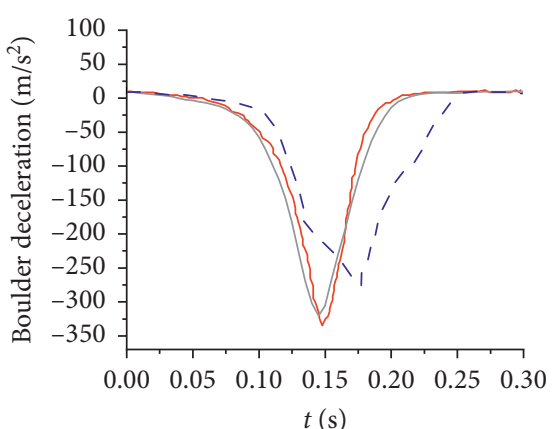

$t(\mathrm{~s})$
- Test-[10]
- FEM-this paper
--- FEM-[10]

(a)

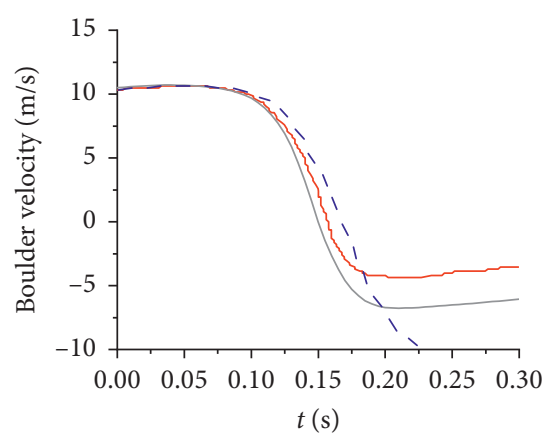

Test-[10]

-- FEM-[10]

(b)

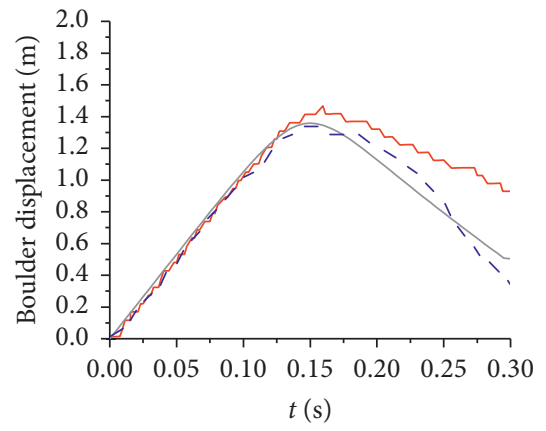

- Test-[10]
- FEM-this paper
-- FEM-[10]

(c)

FIGURE 20: Impact simulation results and test data: (a) boulder deceleration, (b) boulder velocity, and (c) boulder displacement for $n_{\mathrm{w}}=7$.

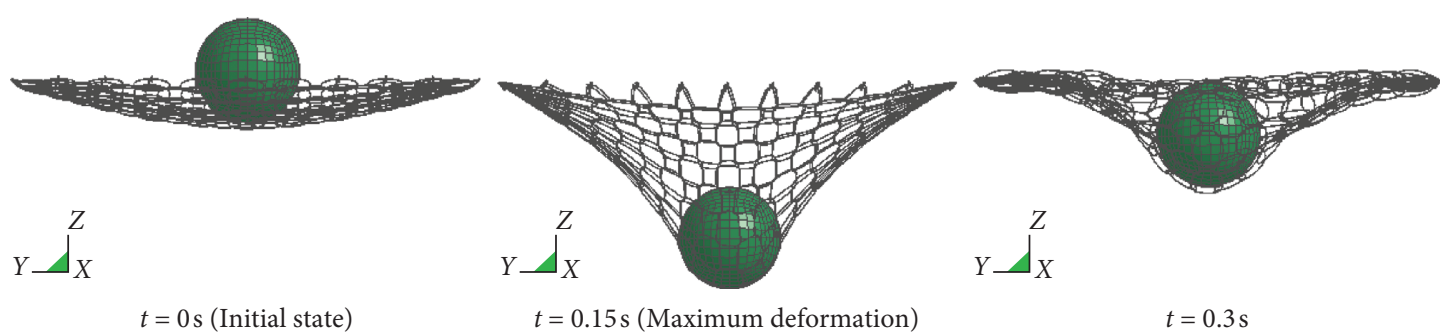

(a)

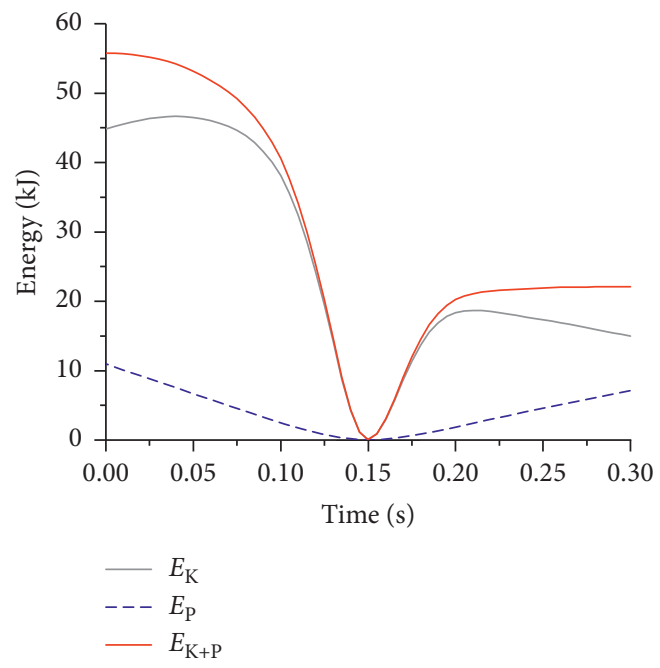

(b)

FIGURE 21: The impact test on wire-ring net during $5.5 \mathrm{~m}$ dropped boulder: (a) simulated deformation of the wire-ring net and (b) evolution of kinetic energy and potential energy. 


\section{Validation with Fully Featured Rockfall Protection Systems}

The full-scale impact test was carried out on rockfall protection barriers with an impact energy of $250 \mathrm{~kJ}$. At the same time, a systematic impact dynamic model is constructed based on the numerical model proposed in this paper. Then, the impact test results are compared with numerical results to verify the applicability of the numerical model. The test model is composed of steel post, net, upper major support cable, lower major support cable, minor support cable, side support cable, upslope anchor cable, lateral anchor cable, energy dissipators, and other components. The support cables and the upslope anchor cables were equipped with the load cell (Figure 22).

5.1. Protection Barrier Configuration. The main components of rockfall protection barrier are shown in Table 6, and the nominal tensile stress of the steel-core cable is $1770 \mathrm{MPa}$.

The installed rockfall protection barrier is presented in Figure 23. One end of the side support cable is tied to the post head, and the other end is connected to the post bottom. One end of the lateral anchor cable is tied to the post head, and the other end is anchored to a reinforced concrete reaction wall. The upslope anchor cable is anchored to the $\mathrm{RC}$ reaction wall at one end, while the other end is tied to the post head with the angle between the upslope anchor cable and the horizontal plane reaching $38^{\circ}$. For the side post, the upper support cable and the lower support cable can slide through the shackles of the post head and the post bottom, respectively. Both ends of the support cable are anchored to the $\mathrm{RC}$ reaction wall. For the middle post, the upper support cable and the lower support cable can also slide through shackles of the post head and the post bottom, respectively. In order to prevent the wire ring from being jammed on the head or bottom of the middle post when the system is impacted, a minor support cable is used to connect the net at the post head or post bottom, and both ends of the minor support cable were tied to the support cable by rope clamps. The bottom of the post is constrained to the support on the $\mathrm{RC}$ reaction wall through a plane pin shaft, which allowed a certain plane rotation. The interception structure is supported by four steel posts inclined at $10^{\circ}$ angles with respect to the horizontal plane. Both ends of the upper/lower major support cable are connected parallelly with two energy dissipators, while the upslope anchor cable is connected with one energy dissipator.

5.2. Experiment Method. The OST test site (Figure 23) located in Guanghan (Sichuan, China) is one of the artificial types, in which the three-functional-module barrier test model, fixed on a $\mathrm{RC}$ reaction wall, is subjected to the impact load vertically at the center. The full-scale impact test is conducted in accordance with the European code [4], and the impactor is concrete polyhedral block with mass of $0.75 \mathrm{t}$ confined by steel plates, and it is raised to the height of $33.8 \mathrm{~m}$ from the barrier plane by crane with an impact energy of $250 \mathrm{~kJ}$. A high speed camera is put right ahead of the test model to record the process of impacting with a frequency of $500 \mathrm{~Hz}$, so that the trajectory of the intercepted block can be captured. Through dynamic acquisition system, the time-force curves of cables are measured to obtain the dynamic response and load paths of the structure, with the acquisition frequency of $1000 \mathrm{~Hz}$.

\subsection{Numerical Approach}

5.3.1. Modeling of the Components. The material properties of net can refer to Table 3 , which will not be elaborated further. Table 7 shows the material properties of steel post, cable, and impactor. The steel wire cables are only considered to be under tension in this study. Cable-discrete element is a unique element used to simulate cable in LSDYNA, which can only withstand tension. So, the cablediscrete element is used to be the modeled cable in this study [23]. While the steel post components are simulated by means of user-defined integration beam element with I-shaped cross-section, on which 9 integration points are defined, the impactor is modeled using solid element.

All the energy dissipators adopted in this study are socalled brake rings with a length of aluminum sleeve equaling to $80 \mathrm{~mm}$, an inner diameter of steel tube ring equaling to $420 \mathrm{~mm}$, a cross-sectional diameter of the tube equaling to $42 \mathrm{~mm}$, and a thickness of the tube equaling to $6 \mathrm{~mm}$ (Figure 24(a)). The tensile force-displacement curves are shown in Figure 24(b), which has obvious phases [14, 26]. The average activation force is set to $51 \mathrm{kN}$, and the corresponding displacement is $100 \mathrm{~mm}$; then, for the yield branch, the average working force increases up to $80 \mathrm{kN}$ till $1000 \mathrm{~mm}$ is reached. Then, the dissipator behaves as a single cable in the corresponding hardening branch. In practical engineering, the failure load of the brake ring should be equal that of internal rope, and the brake ring is considered to be ineffective when the internal rope is fractured in this study. The three characteristic points of the simplified curve are as follows: $100 \mathrm{~mm}, 51 \mathrm{kN} ; 1000 \mathrm{~mm}, 80 \mathrm{kN}$; and $1020 \mathrm{~mm}, 210 \mathrm{kN}$;. In order to improve the computational efficiency, the elastoplastic spring is employed to model the energy dissipator, and the force-displacement of the spring is defined as the simplified curve of the energy dissipator.

5.3.2. Boundary Conditions and Calculation Method. All cable anchorage points are fixed, where six degrees-offreedom (DOFs) are fixed, while the other end of the upslope anchor cable is connected to the head of the post with the coincident node. The post bottom node is completely fixed except releasing the rotational DOF around the vertical axis and horizontal axis, while a constrained spring element is set to simulate the actual horizontal rotation limited by the base plate within a small region [14]. Under the impact load, the steel wire-ring net slips along the support cable, while the upper support cable and lower support cable slip through the head and bottom of the post, respectively. Instead of weaving through the wire-rings, the support cables are attached with the interception net via shackles which are treated as rigid bodies [15]. The slipping feature between the cable and the 


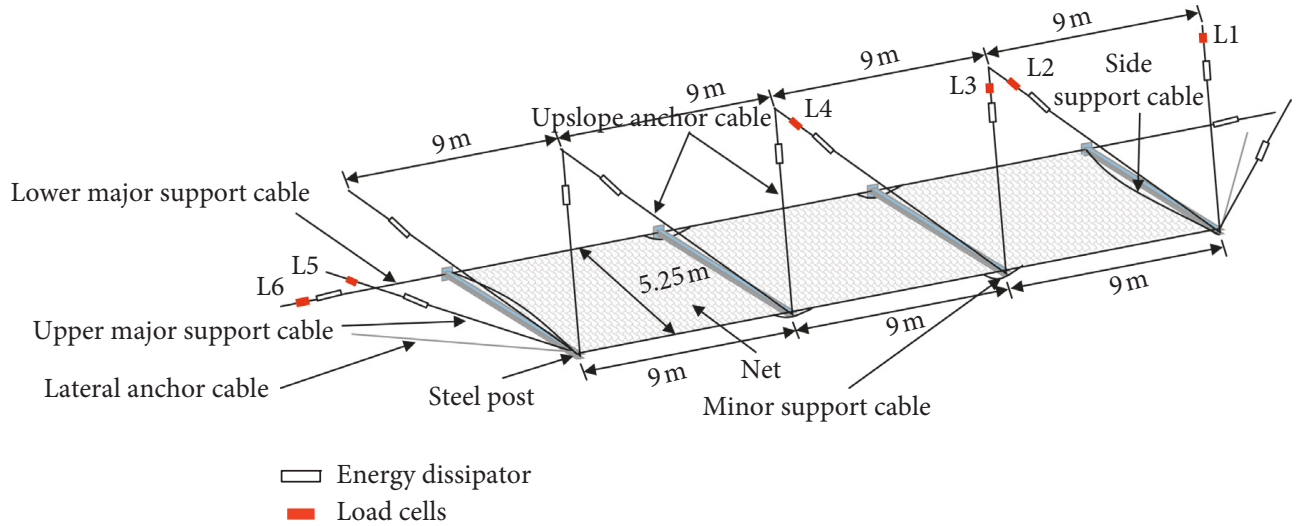

Figure 22: Three-dimensional sketch of the rockfall protection barrier.

TABLE 6: Main component specifications.

\begin{tabular}{|c|c|c|}
\hline The component name & Specifications & Materials \\
\hline Net & $\mathrm{R} 9 / 3 / 300$ & Steel wire \\
\hline Upper/lower major support cable & $1 ø 24$ & $6 \times 19 W+\mathrm{FC}$ \\
\hline Upslope anchor cable & $1 ø 18$ & $6 \times 19 W+\mathrm{FC}$ \\
\hline Minor support cable & $1 \varnothing 18$ & $6 \times 19 W+F C$ \\
\hline Lateral anchor cable & $1 ø 18$ & $6 \times 19 W+\mathrm{FC}$ \\
\hline Side support cable & $1 \varnothing 18$ & $6 \times 19 W+\mathrm{FC}$ \\
\hline Steel post & HW $150 \times 150 \times 7 \times 10$ & Q345 \\
\hline Energy dissipator & GS-8002 & \\
\hline
\end{tabular}
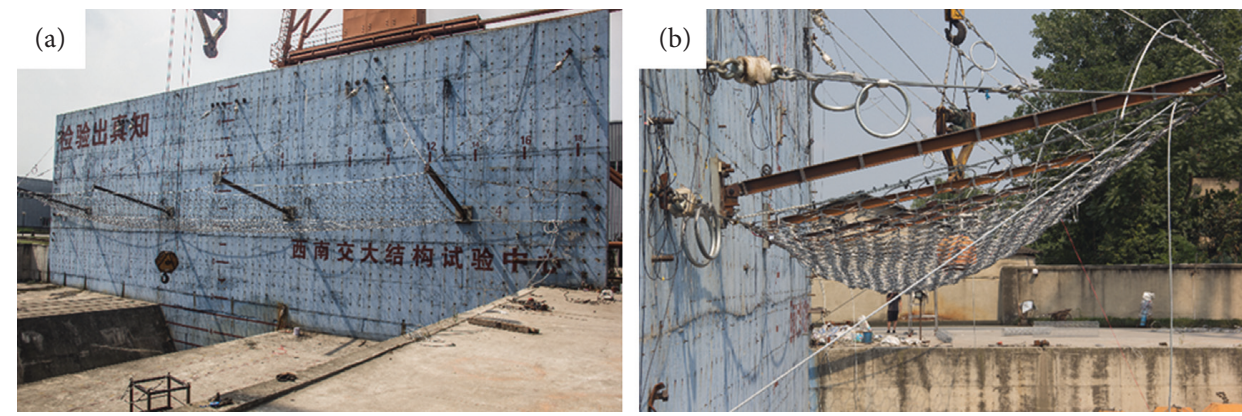

FIgURE 23: Test model of the rockfall protection barrier: (a) a view of the test setup and (b) left view.

TABLE 7: Material properties of components.

\begin{tabular}{lcccccc}
\hline Component & Density $\left(\mathrm{kg} / \mathrm{m}^{3}\right)$ & Poisson's ratio & Elastic modulus $(\mathrm{MPa})$ & Yield stress $(\mathrm{MPa})$ & Material type & Ultimate strain \\
\hline Steel wire rope & 7900 & 0.3 & 150000 & 1770 & Ideal elastic-plastic & 0.03 \\
Steel post & 7900 & 0.3 & 200000 & 345 & Ideal elastic-plastic & 0.3 \\
Impactor & 2500 & 0.2 & 30000 & - & Rigid & - \\
\hline
\end{tabular}

post is implemented by using the seatbelt element [14], which makes cables slip through a point acting like a pulley system. The contact force between the impactor and the net is calculated by automatic beam to surface contact algorithm. Automatic general contact algorithm is employed to enable the wire-rings, cables, and shackle to be mutually confined. Frictional interactions induced energy dissipation. The assumed general dynamic friction coefficient is $\mu_{\mathrm{d}}=0.1$.
However, different dynamic friction coefficients are assumed for two contact interactions: (1) a dynamic friction coefficient of $\mu_{\mathrm{d}}=0.4$ is used to model the concrete block-ring net interaction and (2) a dynamic friction coefficient of $\mu_{\mathrm{d}}=$ 0.2 is used to model the interaction between shackles and cables [15]. To accurately simulate impact response characteristics of the models, a viscous damping coefficient was considered, and the value was assumed as 0.05 [14]. 


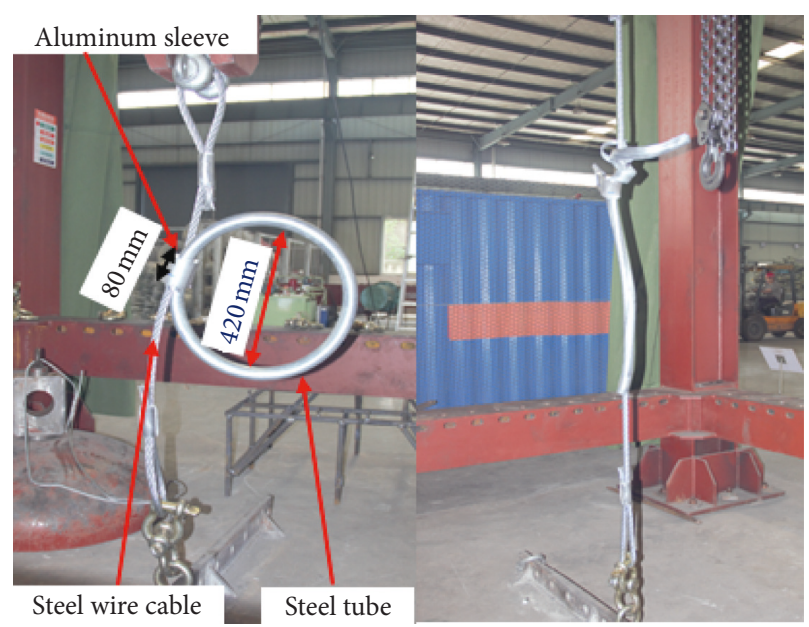

(a)

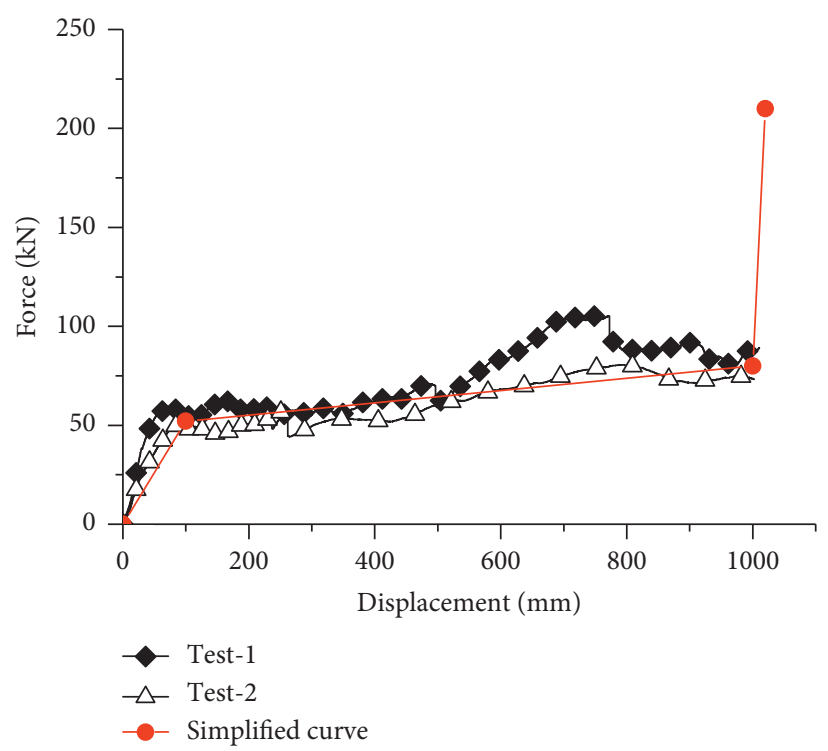

(b)

FIgURE 24: The model of energy dissipators: (a) components and (b) the tensile force-displacement curves.

Before the impact, a form-finding analysis is conducted to ascertain the initial deflection of the wire-ring net under gravity load. The specific algorithm is described in detail by LS-DYNA [23]. The duration of the impact simulation was set to $0.5 \mathrm{~s}$, which approximately represented the impact process. During the impact process, the automatic time step was used. This means that the program automatically calculates the limit value of the time step [23].

\subsection{Approach Assessment: Numerical versus Experimental} Results. After having presented the modelling procedure, the simulation results can be compared with the experimental data to assess the reliability of the proposed approach in capturing the barrier response to an impactor. The accuracy of the wire-ring model directly affects the impact dynamic response of the system, protective structure elongation, and internal forces of cables. In particular, the main parameters such as elongation and forces at the anchoring points are discussed.

5.4.1. Elongation. The impact process of the test (column 1) and the numerical simulation (column 2) and the timedynamics curve of block (column 3) are shown in Figure 25. The deformation pattern, including the shape of the net surrounding the block, is in good agreement with the experiments. The overall response of the barriers is satisfactorily reproduced in the numerical simulations.

The deformed shape of the prototype from the video cameras and that of the model are essentially alike, thereby showing the model's ability to successfully replicate the barrier's fundamental behavior under dynamic conditions. The experimental time-elongation trend has been evaluated by counting the number of frames taken at a constant time interval by means of a high-speed camera, and the numerical predictions satisfactorily agree with the experimental results. The maximum net elongation during the test is $4.77 \mathrm{~m}$, while the calculated elongation is $4.62 \mathrm{~m}$ (a difference of $0.15 \mathrm{~m}$ ). In addition, since Zhao et al. [14] did not consider the contact with sliding friction and the flattening effect of rings at the contact zones, the calculated maximum elongation is smaller than the experimental one, and the calculated maximum acceleration of Zhao et al. [14] is bigger than that in this paper.

5.4.2. Anchorage Forces. The measured anchorage force of cables is compared with the simulation value. It can be found from Figure 26 that the complete process from loading to unloading is recorded by loading cells. The numerical simulation successfully replicates the trend of the force timehistory response. The test and simulation curves of load cell L5 are quite different, mainly because an energy dissipator on the upper major support cable is damaged under the impact load. The force time-history curves are in good agreement with the simulation in this study. On the other hand, the simulation results obtained by using the method of Zhao et al. [14] are in good agreement with the main trend of the test curves. For peak force comparison of cables (Table 8 ), a $15.1 \%$ of maximum value occurs at load cell L1 in this study, and a $50.9 \%$ of maximum value occurs at load cell L3 from the method of Zhao et al. [14]. This shows the reliability of the numerical simulation results and the accuracy of the numerical model of wire-ring net for the actual barrier structure in this study.

\section{Conclusions}

The wire-ring net, one of the several net types, exhibits interestingly complex nonlinear properties, making its usage advantageous for a wide range of engineering protection 
$t$ (s)
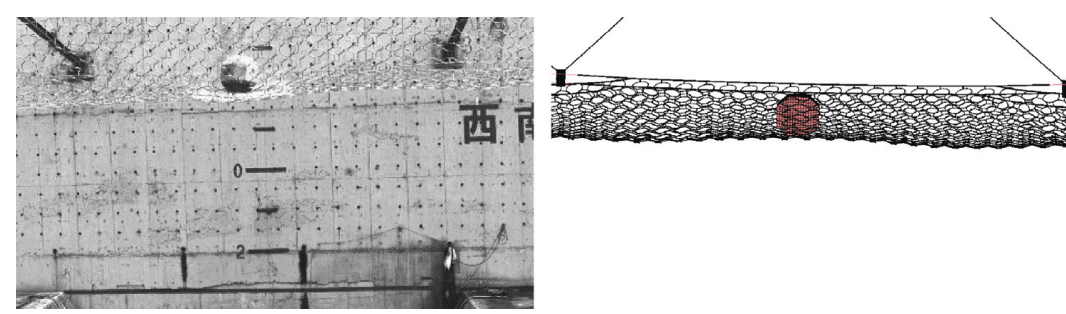

$t=0 \mathrm{~s}$

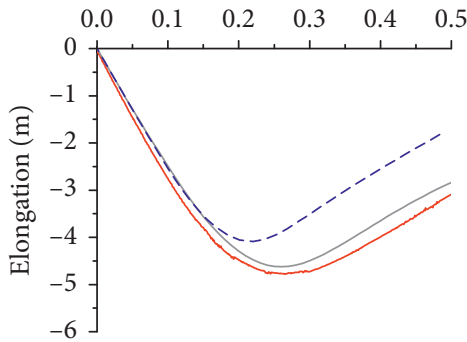

— Test

FEM-this paper

- - FEM-[14]

(a)
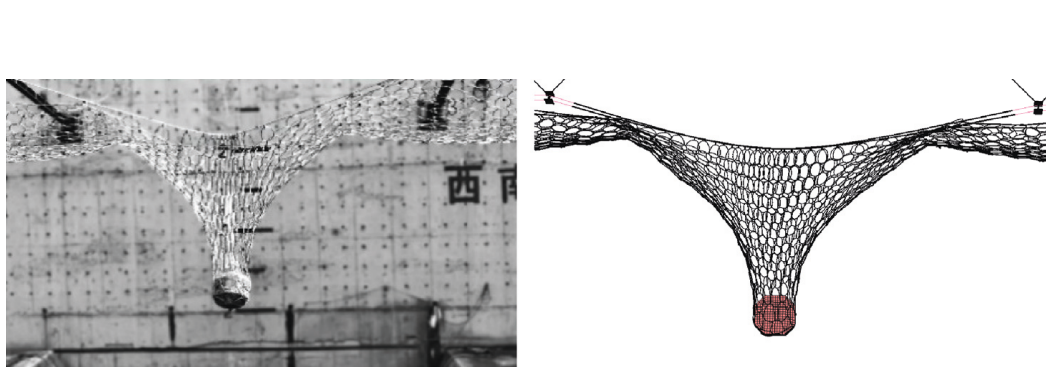

$t=0.15 \mathrm{~s}$

$t$ (s)

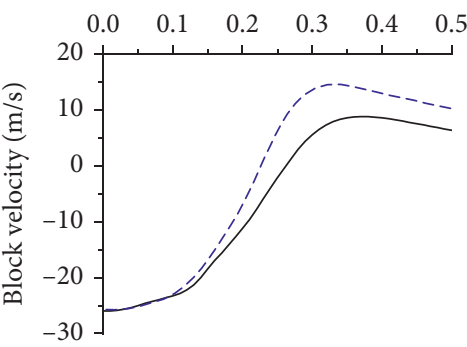

$$
\begin{aligned}
& \text { — FEM-this paper } \\
& \text {--- FEM-[14] }
\end{aligned}
$$

(b)
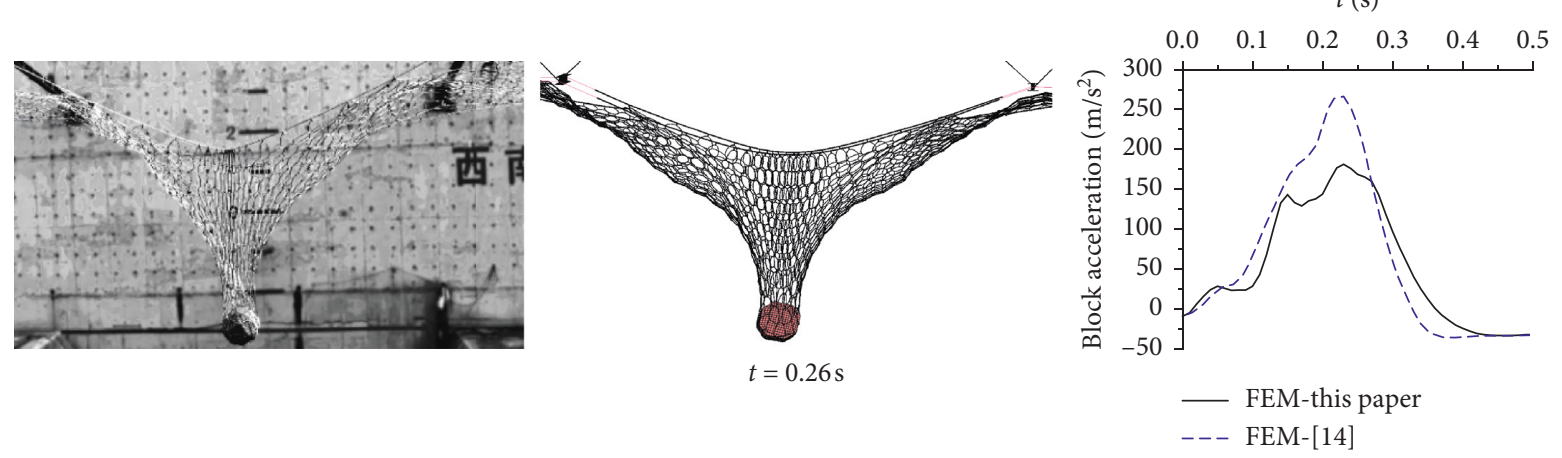

(c)
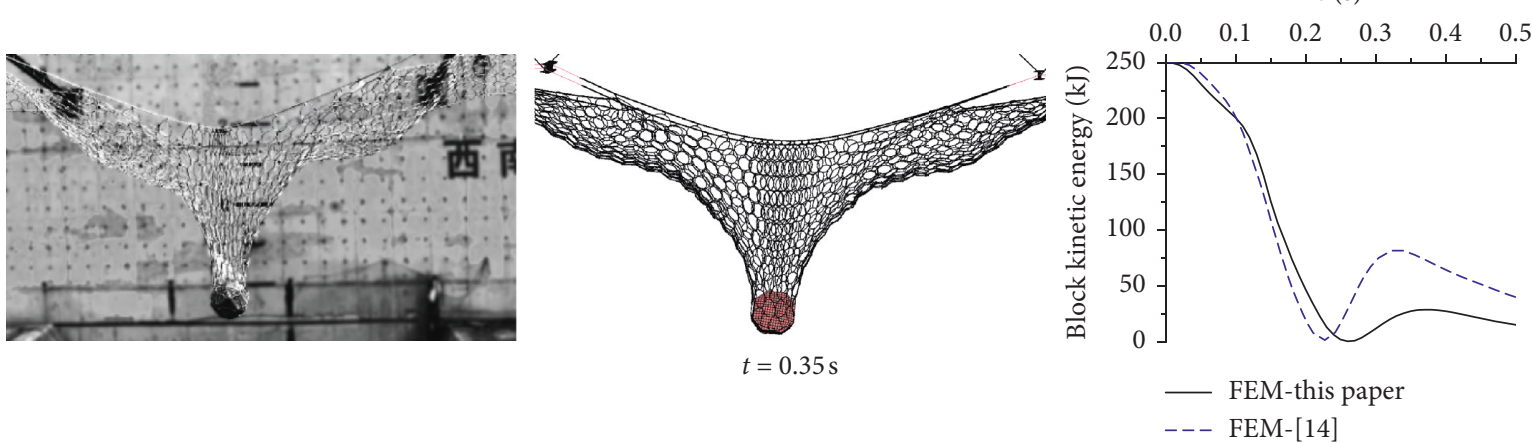

(d)

Figure 25: Experimental video frames (first column), simulation video frames (second column), and block dynamics. 


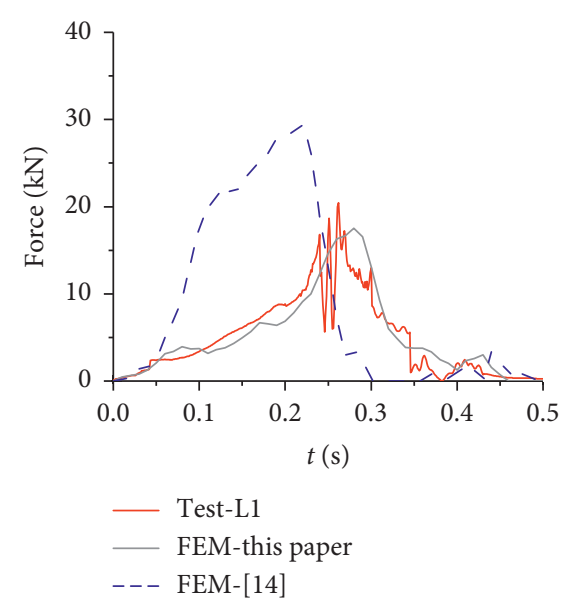

(a)

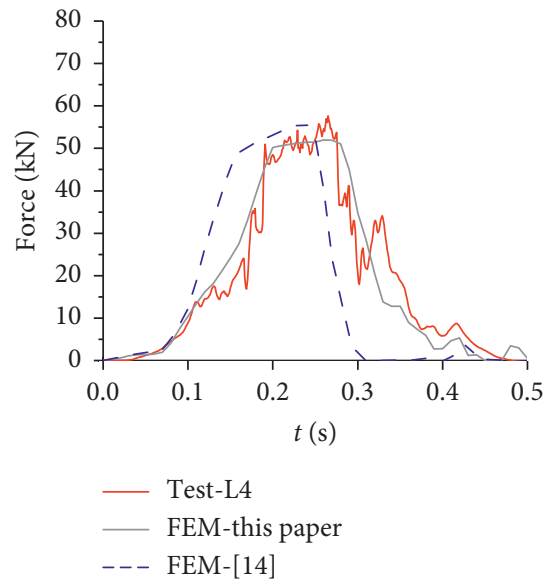

(d)

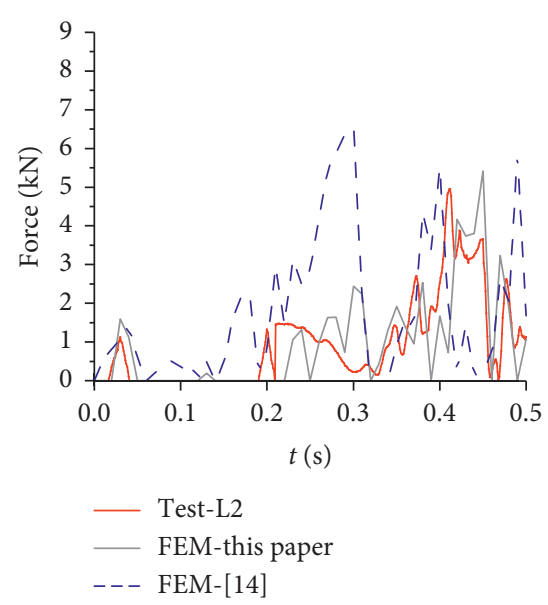

(b)

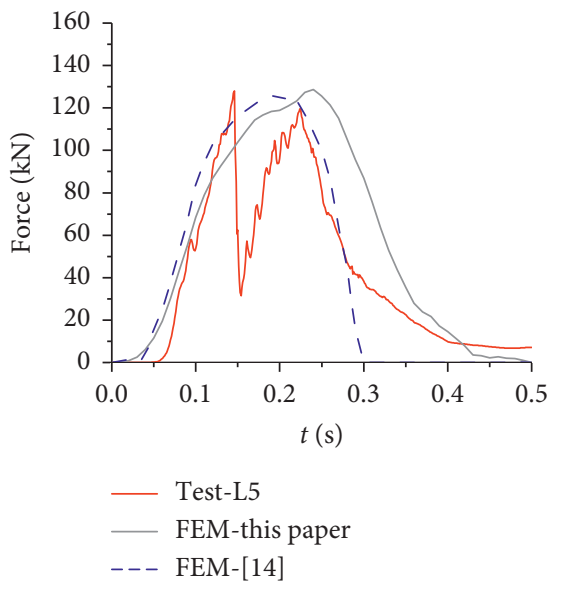

(e)

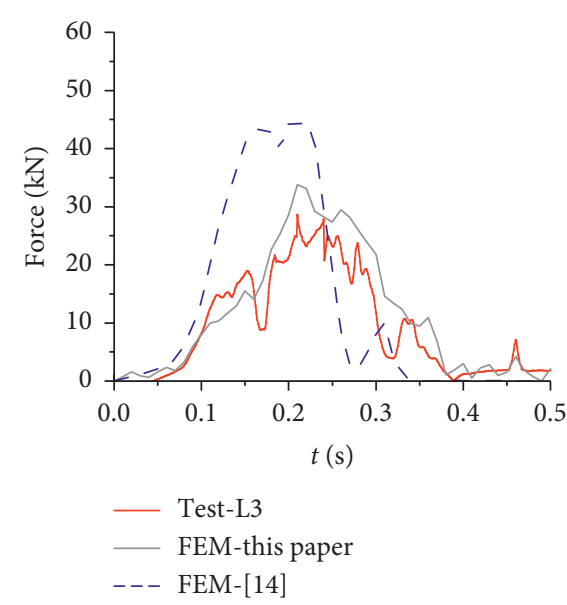

(c)

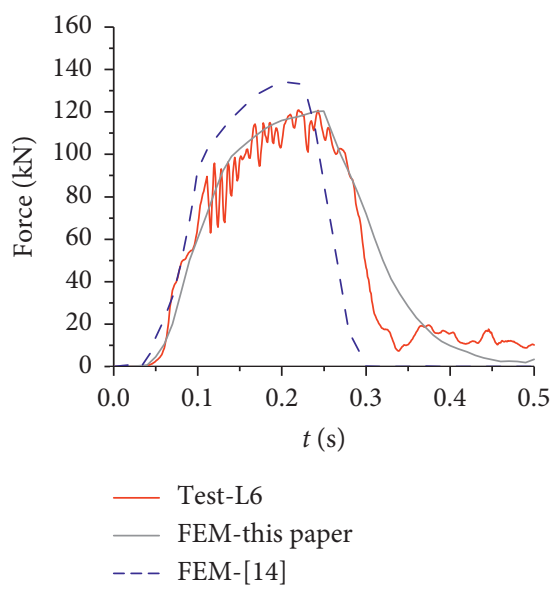

(f)

FIgURe 26: Comparison of force response between simulation and test results: L1-L4 load cell on upslope anchor cables, L5 load cell on upper major support cable, and L6 load cell on lower major support cable.

TABle 8: Peak force comparison.

\begin{tabular}{|c|c|c|c|c|c|}
\hline \multirow{2}{*}{ Load cell } & \multicolumn{5}{|c|}{ Peak force $(\mathrm{kN})$} \\
\hline & Test & FEM-this study & Error $(\%)$ & FEM [14] & Error $(\%)$ \\
\hline L1 & 20.5 & 17.4 & -15.1 & 29.2 & 42.4 \\
\hline $\mathrm{L} 2$ & 5.0 & 5.4 & 8 & 6.5 & 30 \\
\hline L3 & 29.3 & 33.7 & 15.0 & 44.2 & 50.9 \\
\hline L4 & 57.8 & 52.2 & -9.7 & 55.6 & -3.8 \\
\hline L5 & 129.0 & 128.3 & -0.5 & 125.8 & -2.5 \\
\hline L6 & 121.0 & 121.7 & 0.6 & 133.6 & 10.4 \\
\hline
\end{tabular}

structures. This paper presented a new model that comprehensively covers the nonlinear behaviors of the wire-ring net, leading to the following conclusions:

(1) Quasi-static tests, including tensile tests on steel wires and one-ring specimens, and puncturing tests on net specimens, were conducted. Based on the test results, the axial constitutive curves of steel wires were obtained. The linear correlation equations for the breaking loads of the one-ring specimens and the puncturing strength of wire-ring nets were established, both of which were related to the number of windings. The affected zone length of the flattening effect was also quantified.

(2) The wire ring was modeled via an equivalent beam element with a single winding and a circular cross section. Equivalence between the numerical and actual wire ring in terms of bending and tensile strength, total mass, contact with sliding friction, and rupture behavior was derived and presented. In particular, the emphasis was on simulating the flattening effect, a phenomenon rarely accounted for in conventional numerical models. All dominant 
factors were reflected in a model with the material law by the input of material parameters, and only the ultimate plastic strain, related to the number of elements in a single ring, the number of windings, and the loading configuration of wire rings, needed to be determined through the inverse formulation according to test data. The proposed numerical method provides effective and robust tools to obtain the model parameters for any given ring technology.

(3) The model was calibrated and verified against the experimental data from the two-point traction of the wire ring. To verify the wire-ring net, ensuring calculation efficiency, 32 elements were in a single ring. The proposed mechanical model was calibrated and verified by the data from the wire-ring net tests, and all of these validations reflected the high precision of the numerical model of the wire-ring net.

(4) The FE simulation results of the full-scale test show a good agreement not only in terms of force histories but also in terms of barrier deformation. This also suggests the accuracy of the models implemented for the energy dissipating devices and the wire ring net. However, modeling connections and contact in a realistic manner comes at higher computational cost with respect to other modeling schemes.

The equivalent numerical model of this paper obviously improves simulation accuracy. For $n_{\mathrm{w}}=3$, 4, or 5, equation (10) gives a minimum bending stiffness. However, for $n_{\mathrm{w}}=9$, 12 , or 16 , equation (10) gives a minimum bending stiffness, which may not be suitable, because not all the windings are placed next to each other, but still some are on top of others. This may not be particularly rigorous, but we can only consider this as a hypothesis now for $n_{\mathrm{w}}=9,12$, or 16 . So the flattening effect at the contact zones should be further studied about the value of bending stiffness.

\section{Data Availability}

The data used to support the findings of this study are available from the corresponding author upon request.

\section{Conflicts of Interest}

The authors declare that they have no conflicts of interest.

\section{Acknowledgments}

The work in this study was supported by the National Key R\&D Program of China under grant no. 2018YFC1505405, the Natural Science Foundation of China under grant no. 51678504, the National Key Research and Development Program of China under grant no. 2016YFC0802205, the Department of Science and Technology of Sichuan Province under grant nos. 2018JY0029 and 2019YJ0221, the Science and Technology Research and Development Program of China Railway Corporation under grant no. 2018KY10, the Shock and Vibration of Engineering Material and Structure Key Laboratory of Sichuan Province under grant no. 18kfgk07, and the Transportation Science and Technology Project of Sichuan Province under grant no. 2018-B-03.

\section{References}

[1] C. Liu, Z. Yu, and S. Zhao, "Quantifying the impact of a debris avalanche against a flexible barrier by coupled DEM-FEM analyses," Landslides, pp. 1-15, 2019.

[2] J. P. Escallón, V. A. Boetticher, C. Wendeler, and P. Bartelt, "Mechanics of chain-link wire nets with loose connections," Engineering Structures, vol. 101, pp. 68-87, 2015.

[3] K. Thoeni, C. Lambert, A. Giacomini, and S. W. Sloan, "Discrete modelling of hexagonal wire meshes with a stochastically distorted contact model," Computers and Geotechnics, vol. 49, pp. 158-169, 2013.

[4] European Organisation for Technical Approvals, Guideline for European Technical Approval of Falling Rock Protection Kits (ETAG 027), European Organisation for Technical Approvals, Brussels, Belgium, 2012.

[5] D. Bertrand, A. Trad, A. Limam, and C. Silvani, "Full-scale dynamic analysis of an innovative rockfall fence under impact using the discrete element method: from the local scale to the structure scale," Rock Mechanics \& Rock Engineering, vol. 45, no. 5, pp. 885-900, 2012.

[6] J. P. Escallón and C. Wendeler, "Numerical simulations of quasi-static and rockfall impact tests of ultra-high strength steel wire-ring nets using Abaqus/Explicit," in Proceedings of the 2013 SIMULIA Community Conference, Vienna, Austria, May 2013.

[7] A. Trad, A. Limam, D. Bertrand, and P. Robit, "Multi-scale analysis of an innovative flexible rockfall barrier," in Rockfall Engineering, S. Lambert and F. Nicot, Eds., Wiley, Hoboken, NJ, USA, 2011.

[8] Z. X. Yu, L. Zhao, Y. P. Liu, S. C. Zhao, H. Xu, and S. L. Chan, "Studies on flexible rockfall barriers for failure modes, mechanisms and design strategies: a case study of Western China," Landslides, vol. 16, no. 2, pp. 347-362, 2019.

[9] Z. Yu, L. Zhao, L. Guo et al., "Full-scale impact test and numerical simulation of a new-type resilient rock-shed flexible buffer structure," Shock and Vibration, vol. 2019, Article ID 7934696, 16 pages, 2019.

[10] H. Grassl, "Experimentelle und numerische modellierung des dynamischen trag- und verformungsverhaltens von hochflexiblen schutzsystemen gegen steinschlag," Doctoral dissertation, Swiss Federal Institute of Technology ETH Zürich, Zürich, Switzerland, 2002.

[11] F. Nicot, B. Cambou, and G. Mazzoleni, "Design of rockfall restraining nets from a discrete element modelling," Rock Mechanics and Rock Engineering, vol. 34, no. 2, pp. 99-118, 2001.

[12] C. Gentilini, L. Govoni, S. de Miranda, G. Gottardi, F Ubertini, and ., "Three-dimensional numerical modelling of falling rock protection barriers," Computers and Geotechnics, vol. 44, pp. 58-72, 2012.

[13] A. Volkwein, "Numerical simulation of flexible rockfall protection systems," in Proceedings of the International Conference on Computing in Civil Engineering, pp. 1-11, American Society of Civil Engineers, Cancún, Mexico, June 2005.

[14] S. C. Zhao, Z. X. Yu, W. Tao et al., "Test study of force mechanism and numerical calculation of safety netting system," China Civil Engineering Journal, vol. 46, no. 5, pp. 122-128, 2013, in Chinese.

[15] J. P. Escallón, C. Wendeler, E. Chatzi, and P. Bartelt, "Parameter identification of rockfall protection barrier 
components through an inverse formulation," Engineering Structures, vol. 77, pp. 1-16, 2014.

[16] J. B. Coulibaly, M. A. Chanut, S. Lambert, and F. Nicot, "Nonlinear discrete mechanical model of steel rings," Journal of Engineering Mechanics, vol. 143, no. 9, Article ID 04017087, 2017.

[17] International Organization for Standardization, Metallic Materials-Tensile Testing-Part 1. Method of Test at Room Temperature, International Organization for Standardization, Geneva, Switzerland, 2016.

[18] A. Kara, A. Tasdemirci, and M. Guden, "Modeling quasi-static and high strain rate deformation and failure behavior of a $( \pm 45)$ symmetric E-glass/polyester composite under compressive loading," Materials \& Design, vol. 49, pp. 566-574, 2013.

[19] International Organization for Standardization, Steel Wire Ring Net Panels-Definitions and Specifications, International Organization for Standardization, Geneva, Switzerland, 2016.

[20] T. X. Yu and L. C. Zhang, Theory of Plastic Bending and Its Application, Science Press, Beijing, China, 1992.

[21] J. P. Hambleton, O. Buzzi, A. Giacomini, M. Spadari, and S. W. Sloan, "Perforation of flexible rockfall barriers by normal block impact," Rock Mechanics and Rock Engineering, vol. 46, no. 3, pp. 515-526, 2013.

[22] T. X. Yu and X. M. Qiu, Impact Dynamics, Tsinghua University Press, Beijing, China, 2011.

[23] J. O. Hallquist, LS-DYNA Theory Manual, Livermore Software, Technology Corporation, Livermore, CA, USA, 2017.

[24] B. L. Boyce and M. F. Dilmore, "The dynamic tensile behavior of tough, ultrahigh-strength steels at strain-rates from $0.0002 \mathrm{~s}^{-1}$ to $200 \mathrm{~s}^{-1}$," International Journal of Impact Engineering, vol. 36, no. 2, pp. 263-271, 2009.

[25] E. Lehmann and J. Peschmann, "Energy absorption by the steel structure of ships in the event of collisions," Marine Structures, vol. 15, no. 4-5, pp. 429-441, 2002.

[26] L. Castanon-Jano, E. Blanco-Fernandez, D. Castro-Fresno, and F. Ballester-Muñoz, "Energy dissipating devices in falling rock protection barriers," Rock Mechanics \& Rock Engineering, vol. 50, pp. 1-17, 2017. 


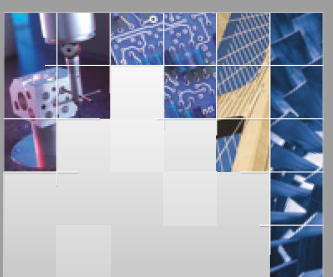

\section{Enfincering}
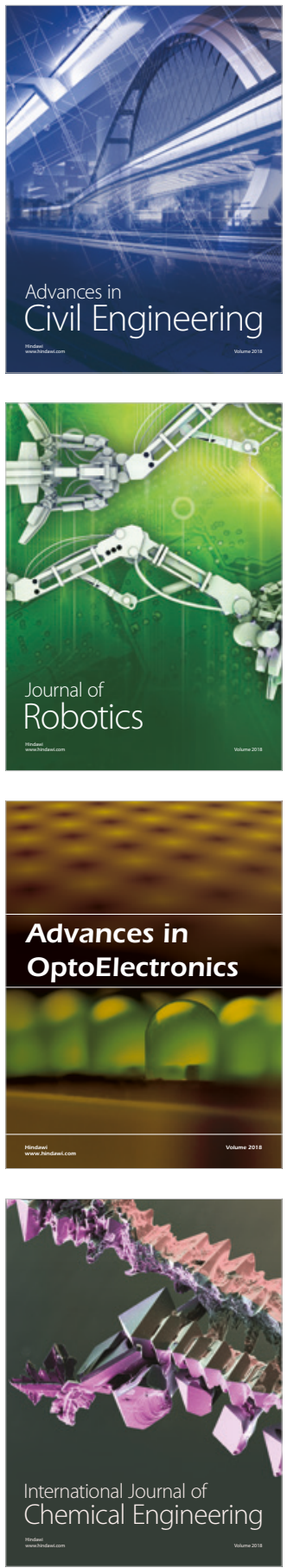

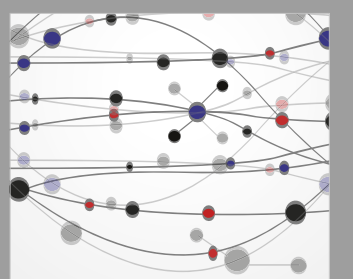

\section{Rotating \\ Machinery}

The Scientific World Journal

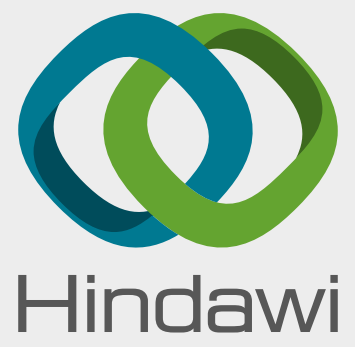

Submit your manuscripts at

www.hindawi.com
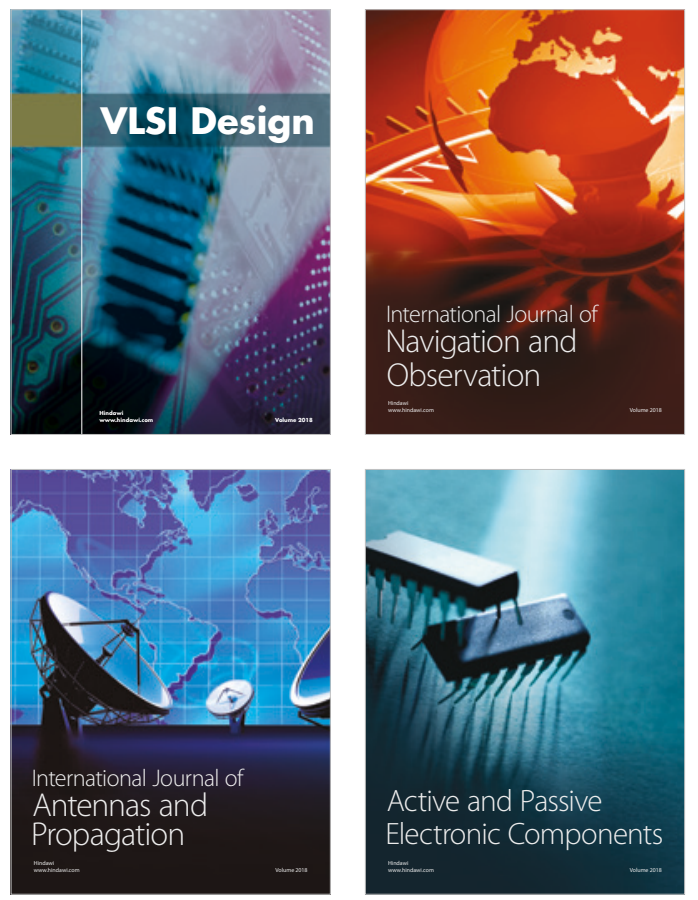
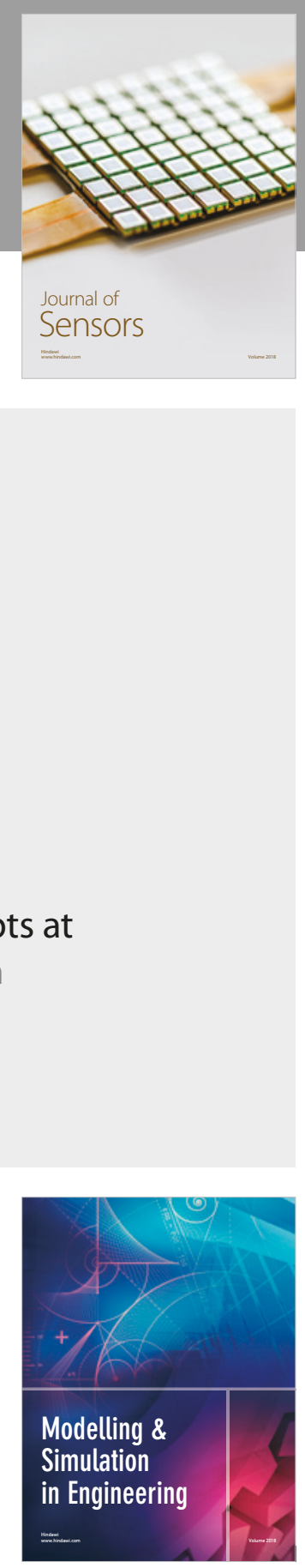

\section{Advances \\ Multimedia}
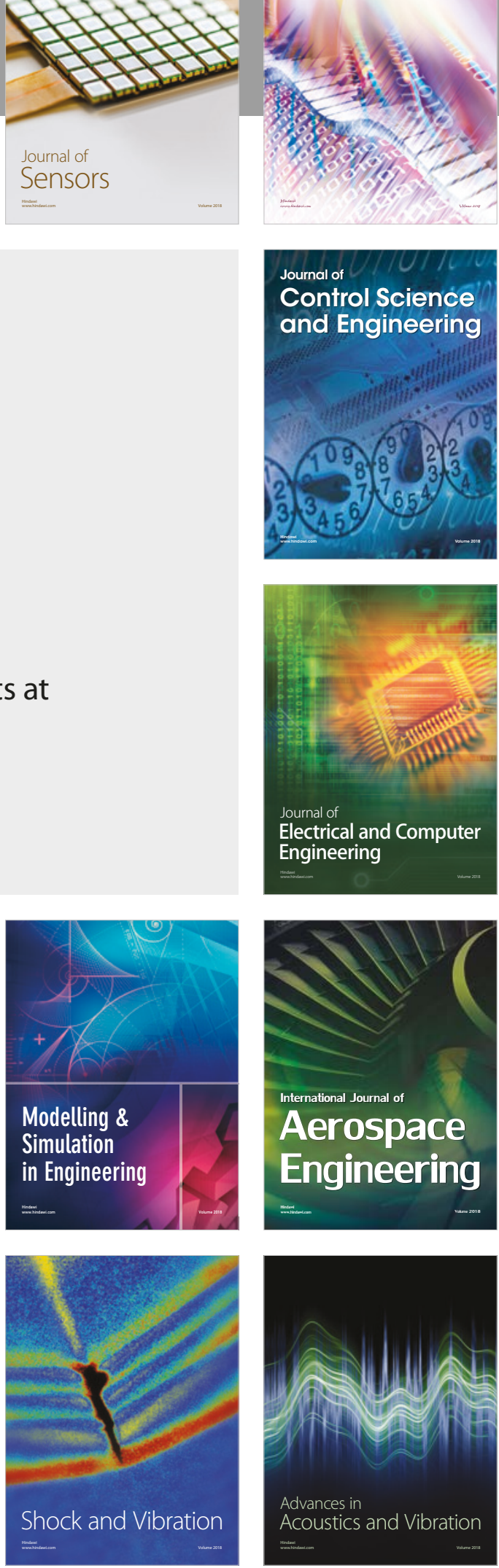